\title{
LAS RELACIONES CONTRACTUALES ENTRE LOS ABOGADOS Y SUS CLIENTES: APORTACIÓN PARA LA RESOLUCIÓN DE LA CUESTIÓN RELATIVA A SU CALIFICACIÓN JURÍDICA
}

THE CONTRACTUAL RELATIONSHIPS BETWEEN ATTORNEYS AND THEIR CLIENTS: CONCERNING THE QUESTION OF THEIR LEGAL STATUS

\section{JONATAN TOBÍO FERNÁNDEZ}

Abogado en ejercicio

Doctor en Derecho -programa de Derecho y Ciencias Sociales de la Escuela Internacional de Doctorado de la Universidad Nacional de

Educación a Distancia (EIDUNED)-

Practicing attorney

Ph.D. in Law - Law and Social Sciences Department of the International Graduate

School of the National University of Distance Education of Spain (EIDUNED)-

Sumario: I. Panorama doctrinal: teorías imperantes. I.A. Teoría del contrato de mandato. I.B. Teoría del contrato de arrendamiento de obra. I.C. Teoría del contrato de arrendamiento de servicios. II. Contratos civiles de obra y servicios en el Código Civil español. III. Criterios jurisprudenciales destacados. IV. Las relaciones contractuales de servicios. V. El sometimiento a una obligación de resultado. VI. Conclusiones. VII. Bibliografía.

Resumen: Desde los años veinte de la pasada centuria, tanto el Tribunal Supremo como la doctrina mayoritaria, han venido sosteniendo que las relaciones jurídico-privadas que establecen los abo- 
gados con sus clientes son encuadrables, por lo común, dentro del tipo contractual del arrendamiento de servicios, definido en el artículo 1544 del Código Civil y regulado en los artículos 1583 a 1587 del mismo cuerpo legal. Sin embargo, a nuestro juicio, existen razones de peso para entender que resulta más preciso ubicar estas relaciones, ordinariamente, dentro de la figura del mandato. Además, aunque la jurisprudencia ha venido sosteniendo la teoría de la locatio conductio operarum -no dejando de aplicar en ocasiones el mandato, o sus reglas, para ciertos supuestos específicos-, en recientes resoluciones el Tribunal Supremo viene manifestando que las relaciones que nos ocupan se desenvuelven, normalmente, en el marco de un contrato de gestión que la propia jurisprudencia construye, de modo no totalmente satisfactorio, con elementos tomados del arrendamiento de servicios y del mandato, por lo que la cuestión aún dista mucho de ser pacífica.

Palabras Clave: abogacía, contrato, mandato, arrendamiento, servicio, obra.

Abstract: Since the 1920's, both the Supreme Court and the majority of legal opinions have supported the classification of the private-law relationships between attorneys and their clients, as a general rule, as service contracts, as defined in Art. 1544 Spanish Civil Code and governed by Arts. 1583 to 1587 of the same code. In spite of this, there are important reasons, in our opinion, that make it more accurate to understand these relationships, in ordinary cases, as an instance of a mandate. Moreover, although case law has supported the theory of locatio conductio operarum - without failing to apply the mandate, or its regulations, to certain specific cases - in recent rulings the Supreme Court has asserted that the relationships in question normally develop within the framework of a management contract, which case law itself constructs, in a not completely satisfactory manner, using elements taken from the service contract and from the mandate, and hence the question is not undisputed by any means.

Keywords: legal profession, contract, mandate, hiring, service, work.

Recepción original: 23-4-2020

Aceptación original: 19-6-2020 


\section{PANORAMA DOCTRINAL: TEORÍAS IMPERANTES}

En primer lugar, a modo introductorio, se realiza un somero análisis acerca del estado doctrinal de la cuestión relativa a las distintas teorías que han venido sosteniéndose respecto a la calificación jurídica de las relaciones contractuales que establecen los profesionales liberales con sus clientes, en el desempeño de la actividad que le es propia, dado que la abogacía se incardina en la categoría de actividades que tradicionalmente reciben tal consideración. Si bien, nos centraremos tan sólo en las teorías que han adquirido mayor calado, consolidándose como prevalentes e imperantes a lo largo de la historia (mandato y arrendamiento de servicios u obra). ${ }^{1}$

\section{A. Teoría del contrato de mandato}

Esta teoría se funda en la distinción establecida en la Roma antigua entre las ocupaciones o profesiones más elevadas, las operae liberales, de carácter intelectual, consideradas como nobles, y las operae non liberales, que requieren para su práctica el trabajo manual o el imprimir esfuerzo físico, motivos por los que se consideran como

1 Por puras razones de economía expositiva, no haremos especial referencia a otras teorías que, bien no han tenido un apoyo doctrinal de cierta entidad, bien no han sido acogidas por la jurisprudencia, al menos de manera reiterada. Así, cierta parte de la doctrina laboralista ha pretendido una ampliación del ámbito de afección del Derecho del Trabajo a las relaciones que nos ocupan, de forma que esta disciplina jurídica debería girar en torno al concepto de profesionalidad; Vid. ALONSO PÉREZ, M ${ }^{a}$.T., Los contratos de servicios de abogados, médicos y arquitectos, Edit. J.M. Bosch Editor, Barcelona, 1997, pág. 65. Teoría del contrato multiforme, defendida por Mosset Iturraspe, quien sostiene que el profesional liberal, algunas veces, promete una actividad y, otras, un resultado, por lo que, en el primer supuesto, la relación contractual que opera es la del arrendamiento de servicios, mientras que, en el segundo, habrá de aplicarse el arrendamiento de obra; Vid. MOSSET ITURRASPE, J., Responsabilidad civil del médico, Edit. Astrea, Buenos Aires, 1979, págs. 104-105. Cierta parte de la doctrina sostiene que las relaciones que se dan entre el profesional liberal y sus clientes responden a un contrato mixto, tal y como defiende Ataz López, argumentando al respecto que los elementos derivados del contrato de arrendamiento serían las prestaciones materiales a las que da lugar y, del mandato, la facultad de revocación concedida en cualquier momento al cliente; Vid. ATAZ LÓPEZ, J., Los médicos y la responsabilidad civil, Edit. Montecorvo, Madrid, 1985, págs. 146-147. Finalmente, se han dado las teorías del contrato innominado, sui generis y atípico, que, como apunta Alonso Pérez, están estrechamente relacionadas con las concepciones previas que se tengan sobre el alcance de los conceptos de estas categorías contractuales; Vid. ALONSO PÉREZ, M ${ }^{\text {a }}$.T., Los contratos de servicios de abogados, médicos y arquitectos, op. cit., págs. 70-71.

(C) UNED. Revista de Derecho uned, núm. 27, 2021 
viles, de la más baja consideración social, y por lo que, en un principio, sólo son ejecutadas por esclavos. ${ }^{2}$

El trabajo manual, retribuido a través de la merces o renta, hunde sus raíces en la existencia de la esclavitud y su especial consideración dentro de la estructura económica del mundo romano antiguo. El esclavo tenía la consideración jurídica de una cosa más en propiedad de su dueño, por lo que el contrato a través del que alguien cedía a un esclavo de su propiedad a otro, recibiendo por ello una renta, en nada podía diferenciarse de la locatio conductio rei $i^{3}$. El objeto del contrato era la persona del trabajador y no su trabajo ${ }^{4}$. Mas, ya desde la época clásica, se plantea el problema de que ese tipo de trabajos manuales, en los que prima el uso de la fuerza física, considerados como serviles, pasan a ser desempeñados por ciudadanos libres ${ }^{5}$. Sus causas se remontan a la época Republicana, ya que a partir de mediados de este período, fruto de la extensión de las fronteras romanas por las guerras de conquista, es cuando se produce el cambio de una economía agrícola y pastoril a una economía mercantil de la Roma-mercado, transformación socioeconómica que trae consigo un impacto en el desarrollo del sistema contractual, con aparición de nuevas figuras, cuya innovación más importante reside en la introducción de los contratos consensuales, con su progresiva incorporación al Derecho Civil' ${ }^{6}$. Los hombres libres realizan enton-

${ }^{2}$ Cicerón, en De offic. 1,42,150-151, estructura jerárquicamente las actividades de trabajo y de producción de bienes y servicios, en función de aquellas que se muestran, conforme al decoro, acordes a un ciudadano libre, es decir, cuales son convenientes y decentes, distinguiendo éstas de todas las que considera viles y deshonrosas. Así, ensalza, aparte de la dedicación al foro y a otras actividades agrícolas y comerciales a gran escala, la ocupación en profesiones que requieren un mayor saber y que reportan gran utilidad a la comunidad, como la medicina, la arquitectura y la enseñanza de las "artes liberales", las cuales pueden ser desempeñadas con honor sólo por ciudadanos romanos libres, con la condición social adecuada.

${ }^{3}$ DE ROBERTIS, F., I rapporti di lavoro nel Diritto Romano, Edit. Dott. A. Giuffrè Editore, Milano, 1946, pág. 123; MARTINI, R., Mercennarius, contributo allo studio dei rapporti di lavoro in Diritto Romano, Edit. Dott. A. Giuffrè Editore, Milano, 1958, págs. 15 y ss.

${ }^{4}$ GÓMEZ-IGLESIAS CASAL, A., La influencia del Derecho Romano en las modernas relaciones de trabajo, Edit. Civitas, Madrid, 1995, pág. 30.

5 GÓMEZ-IGLESIAS CASAL, A., La influencia del Derecho Romano en las modernas relaciones de trabajo, op. cit., pág. 37

${ }^{6}$ Los juristas atribuyen el origen de los contratos consensuales -mandato, sociedad, compraventa y arrendamiento- al Derecho de gentes, que se aplicaba a las relaciones entre romanos y extranjeros, tuteladas por el praetor peregrinus, y que posteriormente se encuadran en el Derecho Civil, pudiendo ser aplicadas a las relaciones entre ciudadanos romanos; GARCÍA GARRIDO, M.J., Derecho Privado Romano. Casos-acciones-instituciones, Edit. Ediciones Académicas, Madrid, 2015, pág. 196. En virtud de la lex Aebutia, promulgada aproximadamente en el año 130 a.C., que generaliza el procedimiento per formulas, el pretor debía establecer también en 
ces el trabajo subordinado a través de la locatio conductio operarum y la locatio conductio operis ${ }^{7}$. Los trabajos más bajos realizados por hombres libres, que prácticamente no requerían cualificación alguna, tenían su origen, por lo general, en la relación contractual de la locatio conductio operarum. Al trabajador que se vincula a través de esta modalidad contractual, que coloca su persona o fuerza de trabajo a favor de otros, se le denomina mercennarius ${ }^{8}$. Se le atribuye tal nombre por el hecho de ser recompensado por el trabajo realizado a través de una merces ${ }^{9}$.

Las actividades de mayor consideración social, las nobles, tales como la abogacía, la medicina o la preceptura, entre otras, es decir, las profesiones liberales, no podían ser reguladas por tipos contractuales que supusieran sometimiento e implicasen pérdida de independencia. Además, debían fundarse en la amicitia, porque, en un principio, la gratuidad se erigió en característica esencial de los servicios prestados por los que se dedican a estas actividades, consideradas como un officium o deber de solidaridad entre conciudadanos, hasta que jurídica y formalmente se acaba aceptando la remuneración por los servicios, a modo de honorario (de honor $)^{10}$.

su edicto las fórmulas de las acciones civiles, lográndose con ello que las instituciones derivadas del ius gentium, y los programas redactados para dotarlos de protección jurídica eficaz, fueran incorporados paulatinamente al ius civile; Vid. MARTÍN MINGUIJÓN, A.R., Acciones ficticias y acciones adyeticias, Edit. Dykinson, Madrid, 2001, pág. 6. Respecto a las transformaciones socioeconómicas acaecidas en la República y el impacto que producen en el funcionamiento de los tradicionales contratos, cuya innovación más importante se produce en los dos últimos siglos de esta época, con la introducción de los contratos consensuales, Vid., MONCAYO RODRÍGUEZ, S., Contratos: tradición y globalización, en Transformaciones jurídicas en el contexto de la globalización. Contratos: tradición y globalización, Vol II, Edit. Arana Editores, Xalapa, 2007, págs. 7275.

7 DE ROBERTIS, F., I rapporti di lavoro nel Diritto Romano, op. cit., págs. 121 y ss. De otra parte, en cuanto a la concepción unitaria de la locatio conductio, FERNÁNDEZ DE BUJÁN, F., Sistema contractual romano, Edit. Dykinson, Madrid, 2004, pág. 265.

8 GÓMEZ-IGLESIAS CASAL, A., La influencia del Derecho Romano en las modernas relaciones de trabajo, op. cit., pág. 48

${ }^{9}$ Como afirma Gómez-Iglesias Casal, la denominación de mercennarius podía ser utilizada en un sentido amplio o en un sentido restringido. En su sentido amplio, o genérico, se refería a todas aquellas personas que recibían una merces por la realización de su trabajo. En un sentido más restringido o estricto, designaría sólo aquellos trabajadores que no desempeñan una actividad concreta o especializada, es decir, que no practican un ars, siendo éstas las de consideración social más baja. Vid. GÓMEZ-IGLESIAS CASAL, A., La influencia del Derecho Romano en las modernas relaciones de trabajo, op. cit., pág. 49.

${ }_{10}$ Ello no significa que, con anterioridad, los que se dedicaban a estas actividades, como, por ejemplo, los oratores o advocati, no percibiran recompensa alguna, a modo de expresión de gratitud, por parte del beneficiado por su intervención (consi- 
Por todo ello, gran parte de la doctrina sostiene que las relaciones que se daban entre los profesionales liberales y sus clientes les eran de aplicación las normas y principios rectores del contrato de mandato ${ }^{11}$. Fernández de Buján, F. ${ }^{12}$ afirma que fue frecuente que estos profesionales, y otros muchos que ejercían actividades intelectuales, científicas o artísticas, encuadrasen las relaciones con sus clientes en el ámbito del mandato y no en el arrendamiento de servicios. Sostiene que, en el proceso de evolución social del Principado probablemente comenzó a ser utilizado por personas no vinculadas por lazos de amistad o de parentesco, donde los juristas admitían retribución si se había pactado ${ }^{13}$. A su vez, aduce que, al final de la época clásica, es probable que se admita el mandato retribuido como un supuesto normal, por lo que en ciertos casos el mandatario recibiría retribución, salvo pacto expreso en contrario de las partes, como una consecuencia natural del mismo ${ }^{14}$.

derada como honor). El cumplimiento de la remuneratio no dependía de la libre y espontánea voluntad del cliente, sino que su obligatoriedad venía impuesta por la costumbre y se dirigía a recompensar unos servicios que no eran objeto de retribución; reciprocidad que, por otro lado, encuentra su fundamento en una cierta correspondencia entre la moral estoica y las mores maiorum. De ahí la utilización de honorarium como término que alude a la retribución atribuída a una persona para honrarla, como expresión de gratitud hacia alguien. Vid. AGUDO RUIZ, A., Abogacía y abogados, un estudio histórico-jurídico, Edit. Egido Editorial, Zaragoza, págs. 167-179.

${ }_{11}$ D’ORS, A., Elementos de Derecho Privado Romano, Edit. EUNSA, Pamplona, 2006, págs. 260-261; GARCÍA GARRIDO, M.J., Derecho Privado Romano. Casos-acciones-instituciones, op. cit., págs. 196-198 y págs. 212-; FERNÁNDEZ DE BUJÁN, F., Sistema contractual romano, op . cit., pág. 356; ROSSI, R., Observaciones sobre la figura del abogado en Derecho Romano, en Studi in onore di Giuseppe Grosso, Vol I, Edit. G. Diapidreli, Torino, 1970, págs. 280-290; AGUDO RUIZ, A., Abogacía y abogados, un estudio histórico-jurídico, op. cit., pág. 176; y KASSER, M., Derecho Privado Romano, trad. por Santa CRUZ TEJERIZO, J., Edit. Reus, Madrid, 1982, pág. 206.

12 FERNÁNDEZ DE BUJÁN, F., Sistema contractual romano, op. cit., págs. 356-358.

13 Como afirma Mohino Manrique «los prudentes romanos presidieron su labor desde un esencial sentido pragmático que considera que el Derecho, como ciencia o arte, se concibe para la vida y no para la especulación»; Cfr. MOHINO MANRIQUE, A.L., Pactos en el contrato de compraventa en interés del vendedor, Edit. Dykinson, Madrid, 2006, pág 1. Sobre la gradual posibilidad de recompensar o retribuir de alguna forma a los abogados, Vid. REINOSO BARBERO, F., El abogado romano "specimen Iuridicum inaugurale», en Historia de la Abogacía Española, Vol. I, Edit. Thomson Reuters Aranzadi, Pamplona, 2015, págs. 151-155; AGUDO RUIZ, A., Abogacía y abogados, un estudio histórico-jurídico, op. cit., págs. 165-209; FERNÁNDEZ DE BUJÁN, A., El abogado en Roma, en Historia de la Abogacía Española, Vol. I, Edit. Thomson Reuters Aranzadi, Pamplona, 2015, pág. 59 y pág. 64; ROSSI, R., Observaciones sobre la figura del abogado en Derecho Romano, op. cit., págs. 280-290.

${ }_{14}$ Los textos en los que la retribución se concibe como una consecuencia natural del mandato pertenecen a juristas de la época clásica tardía. Entre ellos destaca un texto de Papiniano, recogido en D.17,1,56,3. En este párrafo el jurista acepta resueltamente la remuneración prometida a un mandatario, siempre que se pacte ex- 
Así, de acuerdo a la tradición romanista, parte de la doctrina francesa del siglo XIX, encabezada por Pothier ${ }^{15}$, sustentó la teoría del mandato como esquema contractual que alberga las relaciones jurídicas que se dan entre el profesional liberal y el cliente, en el desempeño de las funciones inherentes a la actividad que es propia de aquél ${ }^{16}$. El problema surgió, en un principio, al considerar la gratuidad del mandato como elemento esencial de este tipo contractual ${ }^{17}$. No obstante, esta cuestión quedó definitivamente zanjada tras la promulgación del Code, en el que, en su artículo $1986^{18}$, se reconoce la posibilidad de que el mandato sea retribuido. De igual forma, en las postrimerías del siglo XIX, el Código Civil español hace en su ar-

presamente en el momento de celebración del contrato. D.17,1,56,3 Papinianus libro tertio responsorum. Salarium incertae pollicitationis neque extra ordinem recte petitur neque iudicio mandati, ut salarium tibi constituat. Otro texto en el que se admite, de forma general, la retribución en favor del mandatario, viene recogido en D.17,1,12,8, que trata de un mandato ordenado por un patrono a su liberto. El jurista Ulpiano concede al mandatario la actio mandati contraria para reclamar de su mandante los gastos efectuados en la realización del encargo encomendado, después de deducir la remuneración que percibió en el tiempo intermedio. D.17,1,12,8 Ulpianus libro trigensimo primo ad edictum. Inde Papinianus quaerit, si patronus praedium quod emerat, pro quo pretii bessem exsolverat, iusserit liberto suo tradi, ut ille residuum pretii redderet, deinde reddito pretio vendenti fundum patrono libertus consenserit, trientis pretium an libertus possit repetere. et ait, si mandatum suscepit initio libertus, non donatum accepit, contrario iudicio posse eum pretium repetere, quod deductis mercedibus, quas medio tempore percepit, superest: quod si donationem patronus in libertum contulit, videri et postea libertum patrono donasse. Otro texto, de Ulpiano, recogido en D.17,1,6pr., trata el tema sosteniendo que, si en la constitución de un mandato medió honorario en favor del mandatario, a modo de remuneración, habrá acción de mandato (contraria). D.17,1,6pr. Ulpianus libro trigensimo primo ad edictum. Si remunerandi gratia honor intervenit, erit mandati actio. La doctrina más generalizada considera que este texto está alterado por los compiladores, dado que concede la acción de mandato para reclamar la retribución prometida; es muy probable que en la época clásica la única vía judicial posible para reclamar los honorarios sea a través de la cognitio extraordinem, tal y como se nos informa en D.50.13.1; Vid. FERNÁNDEZ DE BUJÁN, F., Sistema contractual romano, op. cit., págs. 354-358. Sobre los errores en el manuscrito Laurentianus sine numero (hiatus y errata), Vid. BARTOL HERNÁNDEZ, F., Errores en el Codex Florentinus, en Revista de estudios histórico-jurídicos, $\mathrm{N}^{\circ}$ 36, Valparaiso (Chile), 2014, págs. 75-100.

15 POTHIER, R.J., Traité du contrat de mandat, en Oeuvres de Pothier, Tomo III, Edit. Chez I’Editeur, París, 1821, pág. 96.

16 DE LA QUINTANA FERGUSON, M., La responsabilidad civil del médico, Edit. Estades, Artes Gráficas, Madrid, 1949, págs. 54-57.

${ }^{17}$ Según Ataz López, este inconveniente lo resolvieron mediante la afirmación de que la promesa de los honorarios no es más que una convención simultánea al contrato, al que le es extraña y que se encuentra simultáneamente yuxtapuesta, tal y como entiende que ocurría en el Derecho Romano, donde los honorarios no podían ser perseguidos por la actio mandati contraria, sino mediante una persecutio extraordinem; Vid. ATAZ LÓPEZ, J., Los médicos y la responsabilidad civil, op. cit., págs. 129-134.

18 Code. art. 1986: Le mandat est gratuit s'il n'y a convention contraire.

(C) UNED. Revista de Derecho uned, núm. 27, 2021 
tículo $1711^{19}$. En ambos códigos, pues, se consagra la posibilidad de que el mandato sea remunerado, tal y como los textos jurisprudenciales de los juristas de la época clásica tardía hicieron en su día, al considerar que, en determinados supuestos, la retribución es una consecuencia natural del mandato.

\section{I.B. Teoría del contrato de arrendamiento de obra}

Como señala Alonso Pérez ${ }^{20}$, no existe, propiamente, una teoría que afirme que todas las relaciones contractuales celebradas por los profesionales liberales, en el desarrollo de la actividad forense que le es propia, deban ser consideradas como contratos de obra, sino que, más bien, las opiniones doctrinales sobre este particular vienen determinadas por el ámbito profesional concreto que sea objeto de análisis. Así, con fundamento en tal premisa, distingue tres direcciones, que provienen de estudios relacionados con la profesión médica, pero que pueden ser aplicables al resto de profesiones liberales, y que se corresponden con las siguientes: 1) todas las relaciones contractuales establecidas por los profesionales liberales en el ejercicio de su actividad son contratos de obra; 2) sólo ciertas relaciones contractuales de los profesionales liberales son contratos de obra; 3 ) ninguna relación contractual llevada a cabo por estos profesionales son contratos de obra.

La primera de las corrientes citadas, que concluye que la relación contractual establecida por el profesional liberal, en el ejercicio de su actividad, ha de ser calificadas como una locatio conductio operis, es defendida por De La Quintana Ferguson ${ }^{21}$. Este autor, en primer orden, niega la existencia de un contrato de arrendamiento de servicios en este tipo de relaciones jurídico-privadas, al menos tal y como lo concibe nuestro vigente Código Civil, debido a la nota de dependencia inherente a este esquema contractual. En segundo orden, fundamenta al respecto que parte de la doctrina francesa de mediados del siglo XX sostenía que el esquema contractual que más se ajustaba a las relaciones jurídicos-privadas que establecían los profesionales liberales con sus clientes es el de la locatio conductio ope-

${ }_{19}$ C.C. art. 1711: A falta de pacto en contrario, el mandato se supone gratuito. Esto, no obstante, si el mandatario tiene por ocupación el desempeño de servicios de la especie a que se refiera el mandato, se presume la obligación de retribuirlo.

${ }^{20}$ ALONSO PÉREZ, $\mathbf{M}^{\mathrm{a}}$.T., Los contratos de servicios de abogados, médicos y arquitectos, op. cit., pág. 65.

${ }^{21}$ DE LA QUINTANA FERGUSON, M., La responsabilidad civil del médico, op. cit., págs. 58-63 
ris, dado que, bajo este contrato, el profesional no se encuentra ligado al locatario por ninguna especie de subordinación, al conservar una independencia plena para la realización de su trabajo, que efectúa cuando cree oportuno, sin imposición alguna de tiempo ni horario. Es decir, lo que importa a este último contrato es el resultado de la actividad, sin considerar cuales sean o no los medios empleados para la consecución del mismo. El escollo relativo al compromiso del resultado, lo salva identificándolo con la realización de la actividad encaminada a un fin, no con la segura obtención de un resultado o beneficio concretos.

La segunda de las direcciones mencionadas, que entiende que sólo ciertas relaciones contractuales de los profesionales liberales son contratos de obra, es la que se ha asentado en la actualidad, adquiriendo cierto peso, tanto en el ámbito doctrinal como en el jurisprudencial. Esta posición niega rotundamente que todas las relaciones jurídico-privadas que establecen los profesionales liberales con sus clientes, en virtud de un acuerdo de voluntades, se puedan subsumir en el esquema de la locatio conductio operis; mas, ello no es óbice para que ciertas actuaciones profesionales llevadas a cabo por aquéllos puedan ser regidas por este tipo contractual ${ }^{22}$.

Por último, en cuanto a la tercera de las direcciones, la referida a que ninguna relación contractual llevada a cabo por estos profesionales son contratos de obra, utiliza como fundamento estructural de apoyo el factor aleatorio del cumplimiento efectivo del fin último perseguido por el prestatario del servicio (cliente) ${ }^{23}$. Así, en el ámbito de la abogacía, no puede prometerse el cumplimiento efectivo de dicho fin último, en la medida en que el contenido de las resoluciones judiciales no puede ser objeto de control por parte de un abogado.

En nuestra opinión, no puede sostenerse que todas las relaciones jurídico-privadas que establecen los profesionales liberales con

${ }^{22}$ Vid. entre otros, GITRAMA GONZÁLEZ, M., Configuración jurídica de los servicios médicos, en Estudios de Derecho Público y Privado ofrecidos al profesor Serrano y Serrano, Edit. Universidad de Valladolid, 1965, págs. 354-352; LLAMAS POMBO, E., La responsabilidad civil del médico, aspectos generales y modernos, Edit. Trivium, Madrid, 1988, pág. 123; ALONSO PÉREZ, Mª.T., Los contratos de servicios de abogados, médicos y arquitectos, op. cit., págs. 150-155; FERNÁNDEZ HIERRO, J.M., Sistema de responsabilidad médica, Edit. Comares, Granada, 1997, págs. 36-37. A modo de ejemplo, cabe destacar cuando un abogado se compromete a elaborar un informe jurídico sobre una determinada cuestión a su cliente; o cuando el médico se compromete a realizar un informe relativo a una exploración o diagnóstico. En ambos casos, el resultado se asocia a la elaboración de los informes, pero no a si la argumentación jurídica o la exploración o diagnóstico son los correctos o no.

${ }^{23}$ ALONSO PEREZ, $\mathrm{M}^{\mathrm{a}}$.T., Los contratos de servicios de abogados, médicos y arquitectos, op. cit., págs. 66-67.

(C) UNED. Revista de Derecho uned, núm. 27, 2021 
sus clientes, en el desempeño de las actividades que le son propias, y en virtud de un acuerdo de voluntades, se incardinan dentro del esquema del arrendamiento de obra. De un lado, porque la subordinación es prácticamente del mismo grado en todos los contratos civiles de trabajo y, de otro, porque, con carácter general, los que desempeñan este tipo de actividades no pueden constreñirse a la consecución de un resultado ${ }^{24}$. Tampoco pueden apoyarse los postulados que defienden parte de la doctrina para vetar radicalmente la aplicación del contrato de obra a cualquier relación que establezca el profesional liberal con su cliente, bajo el fundamento de que éste no puede comprometerse, en supuesto alguno, a la consecución de un resultado $^{25}$. Así, ha de deducirse que ciertas actuaciones específicas de los profesionales liberales se subsumen dentro del esquema de la locatio conductio operis ${ }^{26}$.

\section{I.C. Teoría del contrato de arrendamiento de servicios}

La mayor parte de la doctrina tiende a inclinarse por la teoría del arrendamiento de servicios a la hora de determinar el tipo contractual en el que, con carácter general, deben encuadrarse las relaciones jurídico-privadas que establecen los profesionales liberales en el desempeño de las actividades que les son propias ${ }^{27}$. La jurispru-

${ }^{24} \mathrm{Y}$ es que, de una parte, tal y como afirma Alonso Pérez, la subordinación que existe en las relaciones civiles de trabajo es jurídicamente del mismo grado -si bien a nuestro entender prácticamente del mismo grado de intensidad-y común a todas ellas, con independencia del esquema contractual en el que puedan ser enmarcadas. La subordinación presenta diferencias en una intensidad de grado jurídicamente relevante tan sólo respecto a las relaciones de carácter laboral, en donde es más elevado. De otra parte, si tenemos en cuenta que en la locatio conductio operis se encierra una obligación de resultado y no de medios, en la que el cumplimiento efectivo del mismo se erige en su elemento definidor, no puede pretenderse la aplicación del esquema contractual de obra bajo el argumento de identificar tal resultado con la mera realización de la actividad encaminada a un fin. Cfr. ALONSO PÉREZ, $M^{\mathrm{a}}$.T., Los contratos de servicios de abogados, médicos y arquitectos, op. cit., págs.104 105.

${ }^{25}$ No obstante, en lo que respecta a algunos ámbitos concretos, como los de la arquitectura u odontología, se tiende a la aplicación del contrato de obra a la mayor parte de las relaciones que establecen en el ejercicio de sus respectivas actividades.

${ }^{26}$ Vid. entre otros, GITRAMA GONZÁLEZ, M., Configuración jurídica de los servicios médicos, op. cit., 354-352; LLAMAS POMBO, E., La responsabilidad civil del médico, aspectos generales y modernos, op. cit., pág. 123; ALONSO PÉREZ, M ${ }^{\mathrm{a}}$.T., Los contratos de servicios de abogados, médicos y arquitectos, op. cit., págs. 150-155; FERNÁNDEZ HIERRO, J.M., Sistema de responsabilidad médica, op. cit., págs. 36-37. .

27 Vid. entre otros, ALBALADEJO GARCÍA, M., Derecho Civil. Derecho de obligaciones, Vol. II, Tomo II, Edit. Librería Bosch, Barcelona, 2002, págs. 732-733 y págs. 781-784; LACRUZ BERDEJO, J.L. (Y OTROS), Derecho de obligaciones. Contratos y cuasicontratos. Delitos y cuasidelitos, Tomo II, Vol. Segundo, Edit. Bosch, Barce- 
dencia que emana del Tribunal Supremo parece consolidar esta teoría desde mediados de la pasada centuria, al sostener también en la mayor parte de sus resoluciones la aplicación de la locatio conductio operarum -en el caso concreto de la abogacía, desde los años veinte-.

Tanto esta corriente doctrinal como la jurisprudencia, interpretan la regulación positiva plasmada en los artículos 1583 a 1587 del Código Civil de manera no restringida, por lo que amplían su aplicación a todas aquellas profesiones que no se encuentren bajo el poder de dirección y organización del demandante del servicio y no sean asalariados en sentido estricto, así supongan la realización de trabajos materiales o intelectuales. Sin embargo, en nuestra opinión, lo autores que se inclinan por esta teoría, en lugar de ofrecer razones de peso para justificar la aplicación del arrendamiento de servicios, fundan sus posturas en diversos motivos por los que no creen posible la aplicación del mandato ${ }^{28}$. Argumentos como el que este esquema contractual tan sólo tiene por objeto la realización de actos jurídicos ${ }^{29}$, la posibilidad de que el mandatario quede sometido a las instrucciones del mandante ${ }^{30}$, su esencial revocabilidad ${ }^{31}$, su inexorable unión a la representación ${ }^{32}$ y la desaparición del sustrato sociológico que sirve de base a su aplicación ${ }^{33}$, han venido dándose por la

lona, 1995, págs. 221-224; FERNÁNDEZ HIERRO, J.M., Sistema de responsabilidad médica, op. cit., págs. 41-44; LLAMAS PONBO, E., La responsabilidad civil del médico, aspectos tradicionales y modernos, op. cit., pág. 129; GITRAMA GONZÁLEZ, M., Configuración jurídica de los servicios médicos, op. cit., págs. 367; LASARTE ÁLVAREZ, C., Principios de Derecho Civil. Contratos, Tomo III, Edit. Marcial Pons, Madrid, 2003, págs. 252-253; SERRA RODRÍGUEZ, A., La relación de servicios del abogado, Edit. Tirant lo Blanc, Valencia, 1999, págs. 61-147.

${ }^{28}$ Entendemos, con el debido respeto, que las posturas de los que defienden la aplicación del arrendamiento de servicios llegan a tal conclusión a fuerza de dar argumentos contra la aplicación del mandato, es decir, de hacer un sistemático ejercicio de descarte, más que en encontrar una defensa sólida en los parámetros y caracteres en los que precisamente se cimentan los esquemas de la locatio conductio operarum.

29 ALBALADEJO GARCÍA, M., Derecho Civil. Derecho de obligaciones, op. cit., págs. 732-733 y págs. 781-783.

${ }^{30}$ LENEL, O., La esencia del mandato, en Revista de Derecho Privado, Madrid, 1944, 773.

31 FERNÁNDEZ HIERRO, J.M., Sistema de responsabilidad médica, op. cit., pág. 33 y págs. 41-44.

${ }_{32}$ Como apunta Alonso Pérez, otro de los argumentos que se han dado para no aplicar el contrato de mandato, que opera también como elemento que sirve de fundamento a las teorías que defienden la aplicación de la locatio conductio operarum, radica en afirmar que el mandato siempre va unido a la representación, postura que tiene su origen en el Derecho belga. Cfr. ALONSO PÉREZ, M ${ }^{\mathrm{a}}$.T., Los contratos de servicios de abogados, médicos y arquitectos, op. cit., págs. 64-65.

${ }_{33}$ GITRAMA GONZÁLEZ, M., Configuración jurídica de los servicios médicos, op. cit., págs. 349-350.

(C) UNED. Revista de Derecho uned, núm. 27, 2021 
doctrina para justificar la aplicación del arrendamiento de servicios a las relaciónes jurídicas que aquí nos conciernen.

Sin embargo, opinamos que la tendencia doctrinal proclive al arrendamiento de servicios no es acorde, con el debido rigor, a las perspectivas literal, teleológica e histórica que han de tenerse presentes para la correcta interpretación de las normas jurídicas que regulan el mandato en nuestro Código Civil, al entender que de ellas se desprende que, desde un principio, la voluntad del legislador decimonónico fue precisamente la de someter tales relaciones a este esquema contractual; conclusión que motivamos y razonamos en los apartados siguientes.

\section{CONTRATOS DE OBRA Y SERVICIOS EN EL CÓDIGO CIVIL ESPAÑOL}

Tal y como sostiene Alonso Pérez ${ }^{34}$, nuestro Código Civil, a diferencia de otros cuerpos legislativos homólogos de nuestro entorno,

${ }^{34}$ ALONSO PÉREZ, M ${ }^{\mathrm{a}}$.T., Los contratos de servicios de abogados, médicos y arquitectos, op. cit., págs. 100-103. La autora señala cómo este criterio diferenciador no se detecta en los Códigos Civiles francés e italiano. El legislador italiano, en el vigente Código Civil de 1942, suprimió la figura del contrato de servicios propiamente dichos, para pasar a incluir las relaciones a las que este se refería tanto en la figura contractual que denomina appalt (artículo 1655), como en el que llama propiamente contrato d'opera (artículo 2230, que remite, a su vez, al 2222). Estos tipos de contratos obligan a la prestación de una obra o de un servicio en sentido estricto, pero el primero parte de una organización empresarial dedicada a tal fin y, el segundo, por persona individual. Codice Civile. art. 1655: L'appalto e' il contratto col quale una parte assume, con organizzazione dei mezzi necessari e con gestione a proprio rischio, il compimento di un'opera o di un servizio verso un corrispettivo in danaro. Codice Civile. art. 2230: Il contratto che ha per oggetto una prestazione d'opera intellettuale e' regolato dalle norme seguenti e, in quanto compatibili con queste e con la natura del rapporto, dalle disposizioni del capo precedente. Sono salve le disposizioni delle leggi speciali. Codice Civile. art. 2222: Quando una persona si obbliga a compiere verso un corrispettivo un'opera o un servizio, con lavoro prevalentemente proprio e senza vincolo di subordinazione nei confronti del committente, si applicano le norme di questo capo, salvo che il rapporto abbia una disciplina particolare nel libro IV. Code. art. 1708: Il y a deux sortes de contrats de louage: Celui des choses, Et celui d'ouvrage. Por otro lado, el Código Civil francés de 1804, admite en su artículo 1708 dos tipos de arrendamientos, el de cosas y el de obra, que asimismo es definido en su artículo 1710 como contrato por el que una de las partes se obliga a hacer alguna cosa para otra a cambio de un precio convenido entre ellas. A su vez, dentro de este contrato genérico de obra, se distinguen, en su artículo 1779, tres clases: el de arrendamiento de personal de trabajo que se obliga al servicio de otro; el contrato de transporte; y el de los arquitectos, constructores y técnicos para realizar estudios y otros trabajos. Code. art. 1710: Le louage d'ouvrage est un contrat par lequel l'une des parties s'engage à faire quelque chose pour l'autre, moyennant un prix convenu entre elles. Code. art. 1779: Il y a trois espèces principales de louage d'ouvrage et d'industrie: $1^{\circ}$ Le louage de 
permite distinguir, de todos los contratos a través de los que se encomienda la realización de un trabajo o actividad, entre los de obra frente a los que pueden denominarse de servicios propiamente dichos. En tal sentido, afirma que la sistemática establecida en el Código Civil, a diferencia de lo que ocurre en el italiano o en el francés, permite distinguir, de manera clara, entre ambos géneros de contratos, al punto que opina que tal distinción determina consecuencias jurídicas importantes. Además, señala que, en España, el problema de la especificación del contrato de obra frente al de servicios propiamente dicho se ha planteado siempre, tanto desde el espectro doctrinal como desde el jurisprudencial, en el ámbito del arrendamiento, pero que, sin embargo, ningún obstáculo supone el utilizar los pronunciamientos que se han dado al respecto y adaptarlos a la clasificación genérica que ofrece; afirmación que, por nuestra parte, compartimos plenamente.

Así, nuestro Código Civil recoge, en su artículo 1544, tanto el arrendamiento de obra como el de servicios, y los define, respectivamente, como la situación en la que una de las partes del contrato se obliga a ejecutar una obra o prestar un servicio a la otra por un precio cierto ${ }^{35}$. Por su parte, en sede de mandato, el artículo 1709 define este contrato como aquel por el que una persona, el mandatario, se compromete a prestar algún servicio o hacer alguna cosa por cuenta o encargo de otra, el mandante ${ }^{36}$. En relación con esta última disposición, el artículo 1711 establece que, con carácter general, el mandato es gratuito, salvo pacto en contrario o que la persona que realice el encargo encomendado tenga por ocupación el desempeño de servicios de la especie a que se refiera el mismo, en cuyo caso dicho mandato se presumirá retribuido ${ }^{37}$.

En definitiva, puede sostenerse la existencia, por un lado, de un arrendamiento de obra y de un arrendamiento de servicios propiamente dichos, y, por otro, de un mandato de obra y de un mandato de servicios propiamente dichos. En resumida cuenta, puede estructurarse el sistema de contratos civiles de trabajo en dos vertientes,

service; $2^{\circ}$ Celui des voituriers, tant par terre que par eau, qui se chargent du transport des personnes ou des marchandises; $3^{\circ}$ Celui des architectes, entrepreneurs d'ouvrages et techniciens par suite d'études, devis ou marchés.

${ }^{35}$ C.C. art. 1544: En el arrendamiento de obras o servicios, una de las partes se obliga a ejecutar una obra o a prestar a la otra un servicio por precio cierto.

36 36 C.C. art. 1709: Por el contrato de mandato se obliga una persona a prestar algún servicio o hacer alguna cosa, por cuenta o encargo de otra.

37 C.C. art. 1711: A falta de pacto en contrario, el mandato se supone gratuito. Esto no obstante, si el mandatario tiene por ocupación el desempeño de servicios de la especie a que se refiera el mandato, se presume la obligación de retribuirlo.

(C) UNED. Revista de Derecho uned, núm. 27, 2021 
que se corresponden, respectivamente, con la de los contratos de obra y las de los contratos de servicios propiamente dichos.

Llegados a este punto, deviene como fundamental diferenciar los contratos de obra de los de servicios propiamente dichos, como paso previo y necesario para determinar la calificación jurídica de las relaciones privadas que establecen las partes, en virtud de un acuerdo libre de voluntades. Así, desde la pasada centuria ha tomado fuerza, tanto desde el punto de vista doctrinal como desde el jurisprudencial, utilizar, como criterio diferenciador preponderante entre los contratos de obra y de servicios, la clasificación de las obligaciones que se establece sobre la base del contenido de la prestación o, lo que es lo mismo, la que responde al distinto comportamiento que ha de exigirse al deudor de la obligación ${ }^{38}$.

Esta clasificación distingue entre lo que se ha venido denominando obligaciones de medios o de actividad de las de resultados ${ }^{39} \mathrm{y}$

${ }^{38}$ Como afirma Alonso Pérez, este criterio, el que se fundamenta en la distinta configuración del objeto de la obligación -de medios, o actividad, o de resultadoasumida por el prestador del trabajo, actúa como el definidor a la hora de distinguir los contratos de obra de los de servicios, frente a otros que se han dado, tales como el de la forma de remunerar el trabajo, el de la subordinación, el de la temporalidad, el de la imputación de los riesgos y el de la naturaleza de la prestación; Vid. ALONSO PÉREZ, M ${ }^{\mathrm{a}}$.T., Los contratos de servicios de abogados, médicos y arquitectos, op. cit., págs. 103-112.

${ }^{39}$ La doctrina francesa atribuyó a Demogue el origen de esta clasificación, quien, ya en el año 1921, anotaba que la obligación del deudor no era siempre de la misma naturaleza, ya que podía ser una obligación de resultados o una obligación de medios. El autor precisó que esta división no estaba ausente de analogía con aquella otra del Derecho Penal que clasificaba a los delitos en formales y materiales. Estos últimos se caracterizan por el resultado, en tanto que los primeros se caracterizan por el empleo de medios que ordinariamente conducen a producir un resultado. Así, al proceder a explicar la distinción en sede de obligaciones, el autor plantea y desarrolla someramente veintiocho ejemplos que lo llevan a efectuar la clasificación de las obligaciones en función del objeto de la prestación. Vid. DEMOGUE, R., Traité des Obligations en Général, Tomo V, Edit. Rousseau \& Cie, París, 1923, 538 y ss. Sin embargo, en nuestra opinión, aunque la distinción entre obligaciones de medios y resultado cristalizara doctrinalmente durante el primer tercio de la pasada centuria, pueden encontrarse ciertos antecedentes de la misma en el Derecho Romano. Así, la jurisprudencia clásica, a la hora de distinguir entre la locatio conductio operarum y la locatio conductio operis, hace alusión, en alguna ocasión, a la obligación de obtener un resultado que pesa sobre el que realiza el opus, mientras que, al referirse a la primera, deja claro que no existe tal imposición, al cumplir el prestador del servicio si actúa con la diligencia debida, con independencia de que se logre o no el fin último perseguido con la actividad. En este sentido, en un texto del libro de las "Reglas" de Paulo, recogido en D.19,2,38pr., puede apreciarse con claridad que el que presta un servicio cumple con la obligación cuando hace lo posible por realizar la tarea encomendada, por lo que, en ningún caso, está obligado a alcanzar el resultado perseguido con la realización de la actividad de que se trate. En el supuesto de no alcanzar el resultado perseguido, el prestador del servicio - 
su aplicación al ámbito contractual, sobre todo para diferenciar los contratos de arrendamiento de obra de los de arrendamiento de servicios $^{40}$, ha resultado para gran parte de la doctrina un pilar esencial y determinante, no sólo con carácter general por sus cualidades descriptivas, para intentar concretar y definir el carácter de las obligaciones que competen a los profesionales liberales en relación con los clientes para los que desempeñan su actividad, sino también para determinar la responsabilidad generada por el incumplimiento de las mismas y para concretar el establecimiento de la carga proba-

en este caso el locator- responderá por dolo y también por culpa, es decir, si no ha llevado a cabo su actividad con la diligencia debida. D.19,2,38pr. Paulus libro singulari regularum. Qui operas suas locavit, totius temporis mercedem accipere debet, si per eum non stetit, quominus operaspraestet. En caso contrario, de otro texto de Paulo, recogido en D.50,16,5,1, se advierte que en la locatio conductio operis la obligación asumida por el que realiza el opus -en este caso el conductor- no es de actividad, sino de resultado, dado que, quien recibe la cosa para realizar sobre ella un trabajo, se compromete a la realización efectiva del fin o interés primario perseguidos por el arrendador. D.50,16,5,1 Paulus Libro secundo ad edictum. "Opere locato, conducto" his verbis Labeo significari ait id opus, quod Graeci òpotxlespa [effectum] vocant, non rgon [opus], id est ex opere facto corpus aliquod perfectum. No obstante, como afirma Fernández de Buján F., bajo la expresión locatio conductio, los juristas romanos configuraron, desde finales de la República, una modalidad contractual única en su fisonomía, aunque compleja en sus aplicaciones prácticas. Señala el autor que, desde esta unidad conceptual, fueron los autores de la pandectística alemana los que, sobre la base de formulaciones dogmáticas medievales, y en un intento sistematizador, distinguieron entre tres modalidades en las que pretendieron agrupar todas las variantes que se recogen en las fuentes justinianeas -locatio conductio rei, locatio conductio operis y locatio conductio operarum-. Vid. FERNÁNDEZ DE BUJÁN, F., Sistema contractual romano, op. cit., 271 y ss.

${ }^{40}$ En nuestro Derecho patrio, la distinción entre obligaciones de medios y de resultado ha sido la definitivamente acogida por doctrina y jurisprudencia. Esta distinción comienza en nuestro país utilizándose como argumento para diferenciar los contratos de arrendamiento de obra y de arrendamiento de servicios, en atención al tipo de obligaciones que generan uno y otro. El Tribunal Supremo, Sala Primera de lo Civil, en Sentencia de 4 de febrero de 1950, utilizó por vez primera esta distinción para considerar que, aun admitiendo que los servicios ofrecidos por los letrados, y otros profesionales liberales, constituyen generalmente un contrato de arrendamiento de servicios, la relación contractual entre el abogado y su cliente también puede aparecer como un contrato de obra y establecer que este supuesto se da cuando, mediante remuneración, se obliga a aquél a prestar no propiamente su actividad profesional, sino el resultado producido por la misma, lo cual ocurre, entre otros casos, en el de aceptar el encargo de emitir un dictamen jurídico. STS, Sala Primera de lo Civil, de fecha de 4 de febrero de 1950: [...] Los servicios ofrecidos por los Letrados y otros profesionales liberales constituyen generalmente un contrato de arrendamiento de servicios, pero la relación contractual entre un Letrado y su cliente también puede aparecer como un contrato de obra, cuando aquél se obliga a prestar no propiamente una actividad profesional, sino el resultado producido por la misma, cual ocurre, entre otros casos, en el aceptar el Letrado el encargo de emitir un dictamen [...]

(C) UNED. Revista de Derecho uned, núm. 27, 2021 
toria acerca de si se cumple o no la prestación ${ }^{41}$. Pero, además, en nuestra opinión, la clasificación que nos ocupa también presenta un alto grado de utilidad y virtualidad como elemento transcendental a la hora de distinguir los contratos de obra de los de servicios propiamente dichos.

${ }^{41}$ No obstante, como afirma Lobato Gómez, una parte del sector crítico pone de relieve que la distinción comporta una visión falseada, simplista o deformante de la realidad jurídica, pues entiende que, si se miran las cosas de manera realista, es imposible establecer una distinción nítida y radical entre las obligaciones de medios y las obligaciones de resultado, ya que toda obligación podría ser considerada de medios o de resultado, según el punto de vista desde el cual se contemple. Así, se ha criticado la distinción argumentando que, en definitiva, todas las obligaciones apuntan a la obtención de un resultado e, incluso, desde una posición extrema, que va mucho más lejos, se ha sostenido que todas las relaciones obligatorias son de resultado. Y con una perspectiva contrapuesta, pero similar, se considera que toda obligación supone el empleo de determinados medios y, consiguientemente, todas las obligaciones podrían considerarse como de medios, incluso las encaminadas a producir un determinado resultado, como sucede con las obligaciones de dar. Mas, el mismo autor defiende la plena utilidad de la distinción y considera como gran parte de la doctrina- que la principal virtualidad de la diferenciación entre obligaciones medios y obligaciones resultado se encuentra en el régimen de la prueba, o, de manera más concreta, en la forma de distribuir la carga de la prueba en los supuestos de incumplimiento. Cfr. LOBATO GÓMEZ, J.M., Contribución al estudio de la distinción entre las obligaciones de medios y las obligaciones de resultado, en Anuario de Derecho Civil, Vol. 45, No 2, Madrid, 1992, pág. 665 y págs. 725 y ss. A su vez, Blanco Pérez-Rubio afirma que, si bien esta clasificación no puede ser considerada la summa divissio de las obligaciones, ni con ella se puede responder a todos los problemas que implica el estudio de las obligaciones, ni ser aplicada mecánicamente y a priori por categorías de contratos, lejos de ser una variedad escolástica, sirve para justificar el empleo de dos sistemas diferentes en la determinación del objeto de la obligación (o del contenido de la prestación, si se prefiere) y de la prueba del hecho generador de la responsabilidad contractual y su respectivo ámbito de aplicación, lo que tampoco impide, obviamente, la admisión de variantes y matices dentro de cada una de las dos categorías en estudio. Sostiene este autor, a su vez, que la utilidad y la relevancia jurídica fundamental de la clasificación que nos ocupa es la relativa al régimen de la prueba. Cfr. BLANCO PÉREZ-RUBIO, L., Obligaciones de medios y obligaciones de resultado. ¿Tiene relevancia jurídica su distinción?, en Cuaderno de Derecho Transnacional, Vol. 6, N 2, Madrid, 2014, pág. 55, pág. 63 y pág. 66. Serra Rodríguez sostiene que la distinción entre obligaciones de medios y obligaciones de resultado asume relevancia, fundamentalmente, bajo tres aspectos, que se corresponden con los siguientes: como elemento determinante del contenido de la obligación de hacer, es decir, de la prestación objeto de la obligación; como criterio de imputación de responsabilidad del incumplimiento de la prestación y, por tanto, en tal sentido, como elemento determinante en relación al establecimiento de la carga de la prueba del hecho generador de tal responsabilidad y la contraprueba liberatoria de la misma; y como criterio básico de otra distinción, la del contrato de servicios y el contrato de obra -si bien, en este punto, a juicio de la autora, la distinción adolece de escasa utilidad-. Cfr. SERRA RODRÍGUEZ, A., La relación de servicios del abogado, op. cit., págs. 52 y ss. 


\section{CRITERIOS JURISPRUDENCIALES DESTACADOS}

En los albores del siglo XX, el Tribunal Supremo sostiene que las relaciones jurídicoprivadas que entablan los profesionales liberales con sus clientes deben ser sometidas a la disciplina del mandato. En Sentencia dictada en la Sala Primera, de lo Civil, en fecha de 14 de junio de 1907, que versa precisamente sobre los servicios prestados por un letrado, el alto tribunal considera que los mismos tienen encaje en el contrato de mandato, aun teniendo en cuenta que han de ser retribuidos. Así, estima un recurso de casación interpuesto por la viuda de un letrado que había prestado sus servicios a los albaceas de una testamentaría, al entender que la sentencia recurrida infringe el artículo 1711 del Código Civil, y establece que el profesional tiene derecho a ser retribuido como mandatario de los servicios ${ }^{42}$. Sin embargo, la misma Sala del Tribunal Supremo, en Sentencia de fecha de 27 de diciembre de 1915, adopta una postura un tanto ecléctica al respecto, al calificar los servicios prestados por un letrado tanto de mandato como de arrendamiento de servicios ${ }^{43}$. El alto tribunal es-

42 STS, Sala Primera de lo Civil, de fecha de 14 de junio de 1907: [...] en los trabajos que éste prestó como Letrado á los albaceas y fideicomisarios de la testamentaría [...] en las operaciones preliminares para llevar a efecto la partición del caudal, al absolver á los demandados por estimar la Sala que no se había justificado la importancia de aquéllos, ni podían ser debidamente apreciados por la nota que sin firma y con enmiendas acompañó la recurrente, faltando bases para dictar un fallo condenatorio, es evidente la infracción de los artículos 360 de la ley procesal y 1711 del Código civil que se invocan en los motivos segundo y cuarto del recurso, porque afirmándose en la sentencia [...] prestó como Letrado sus servicios á los albaceas de la testamentaria [...] el derecho á ser retribuido como mandatario de aquéllos está justificado y reconocido sin que pueda obstar á su condenación al pago la falta de bases para determinar su cuantía que puede ser puntualizada en la ejecución de la sentencia, pues si bien por regla general cuando esta contiene condena de frutos, intereses, daños y perjuicios debe fijarse el importe en cantidad liquida o establecer por lo menos las bases para practicar la liquidación, cuando no es posible lo uno ni lo otro, bastará consignar la reserva de fijar su importancia y hacerla efectiva en la ejecución de la sentencia según el precepto antes citado de la Ley de Enjuiciamiento civil [...]

${ }^{43}$ STS, Sala Primera de lo Civil, de fecha de 27 de diciembre de 1915: [...] Considerando que los servicios que por razón de su título académico y en el ejercicio de su profesión como Abogado presta un Letrado al litigante que los solicita, han de ser, salvo pacto en contrario, necesariamente retribuidos, por constituir la ocupación habitual de aquél, y en tal supuesto, lo mismo con el carácter de mandatario, según el precepto del art. 1.711 del Código civil, como en el prestario de aquellos servicios en razón al contrato de arrendamiento de los mismos conforme al art. 1.544 del citado Cuerpo legal, tiene él derecho de exigir su retribución de aquel a quien los prestó, debiendo estimarse en este segundo caso que existió la estipulación del precio cierto, ya que según doctrina legal así se ha declarado, por no ser precisa la determinación de su cuantía, sino que basta la posibilidad de su establecimiento, según la costumbre ó la ley, y siendo evidente que no puede apreciarse a priori la importancia, y, por tanto, la cuantía de los honorarios que en el curso de cualquiera reclamación judicial haya de

(C) UNED. Revista de Derecho uned, núm. 27, 2021 
tima el recurso de casación interpuesto por la viuda de un letrado, que demandó en nombre y representación de sus hijos, herederos $a b$ intestato, resolviendo que los servicios prestados en vida por el causante deben ser cobrados de su cliente y establece la obligación del procurador de este último a pagar tal retribución, ya que las actuaciones ejercitadas por el abogado fallecido han de ser, salvo pacto en contrario, necesariamente objeto de contraprestación remuneratoria a modo de honorarios, por constituir su ocupación habitual, lo que encuentra amparo tanto en el artículo 1544 del Código Civil como en el artículo 1711 del mismo cuerpo legal.

Pero, respecto al ámbito concreto de la abogacía, el alto tribunal, Sala de lo Civil, ya se muestra partidario de la teoría del contrato de arrendamiento de servicios desde la Sentencia de fecha de 25 de febrero de 1920, resolución que se erige en uno de los primeros pronunciamientos judiciales que con mayor firmeza se apartan de la configuración de los servicios prestados por los letrados como propios del contrato de mandato ${ }^{44}$. Idéntica línea es la seguida en la

devengar un Letrado, la costumbre de su retribución y abono sancionada también en el art. 12 de la ley de trámites, ha establecido su determinación a posteriori, mediante la presentación de minuta detallada, en relación con los trabajos prestados y expresión de su cuantía, si bien sujeta por la misma ley á su impugnación, pues no sería justo que ello quedase completamente al arbitrio de una de las partes contratantes y esto sentado, es visto que no es de estimar la infracción alegada en el primer motivo del recurso formulado [...] que por su defunción sin hacerlos efectivos solicita su viuda [...] como representante legal de sus hijos menores de edad, declarados sus herederos abintestato, y á quienes en la partición adjudicado su importe como crédito á percibir, cabe declarar que los preceptos legales del Código civil, en orden al contrato de mandato ó al de arrendamiento de servicios, pues de uno ó de otro puede derivarse la remuneración de los prestados, deben de estimarse condicionados por los especiales de la ley de Enjuiciamiento civil cuando se trata de mandato conferido á los Procuradores para representar en actuaciones judiciales, y de gastos ocasionados dentro del juicio, siendo de aplicación preferente en este caso estos preceptos á los primeros expresados: Considerando que declarado por el art. 5. ${ }^{\circ}$, núm. 5. $^{\circ}$, de la citada ley del Procedimiento civil, que usando el Procurador del poder conferido, queda obligado á pagar todos los gastos que se causasen á su instancia, incluso los honorarios de los Abogados, aunque hayan sido elegidos por su poderdante; y en relación con ese precepto se establece en el art 12, ya citado, el derecho de los Abogados, sin distinción de casos, á reclamar del Procurador que interviene, el pago de los honorarios que hubiere devengado en el pleito, presentando la minuta detallada y jurando que no le habian sido satisfechos, es evidente que, habiendo representado el Procurador [...] á la parte defendida por el Letrado causante, de sus herederos, actores y recurrentes, como todas las partidas de la minuta de honorarios presentada, se refieren á los diferentes pleitos seguidos por aquélla con su marido [...] y son, por tanto, de un carácter de homogeneidad indiscutible, no cabe dudar que dicho Procurador viene obligado á su pago; no pudiendo excepcionar, en cuanto á esta obligación, que aquel derecho sea personalísimo del Abogado [...]

${ }^{44}$ STS, Sala Primera de lo Civil, de fecha de 25 de febrero de 1920: [...] Considerando que el convenio entre un cliente y su Letrado en virtud del cual el primero requiere los servicios profesionales del segundo y éste se compromete a prestárselos, me- 
Sentencia de fecha de 16 de febrero de 1935, dictada en la misma Sala de lo $\mathrm{Civil}^{45}$. En esta resolución, tras delimitar el mandato, la representación y el arrendamiento de servicios, se considera que el tipo contractual aplicable a los abogados ha de ser precisamente esta última figura ${ }^{46}$. Sin embargo, en la misma resolución, al punto se concluye que, para determinadas actuaciones de gestión, de manera eventual y accesoria, pueden ser encomendadas a los abogados gestiones propias del contrato de mandato.

Por otra parte, la Sentencia de fecha de 4 de febrero de 1950, dictada en la misma Sala de lo Civil del Tribunal Supremo ${ }^{47}$, aunque continúa manteniendo que los servicios prestados por los abogados

diante el pago de los correspondientes honorarios, reviste por su propia naturaleza el carácter de un contrato de arrendamiento de servicios del cual se derivan obligaciones y acciones puramente personales entre los contrayentes, sin trascendencia directa ni indirecta respecto a terceros no ligados por el vínculo contractual, de donde se deduce que no habiéndose celebrado ningún contrato de esa clase por el Letrado demandante con los demandados carece aquél de derecho y acción para reclamar de éstos los honorarios devengados defendiendo a Doña Purificación Dorador en el pleito que sobre nulidad de testamento promovieron los actuales demandados, toda vez que, como con acierto estima la Sala sentenciadora, tales honorarios sólo pueden hacerse efectivos, ya por el procedimiento establecido en los artículos 12 , en relación con el $8 .^{\circ}$, de la ley de Enjuiciamiento civil, o bien por el establecido en los artículos 421 y 423, debiendo, en su consecuencia, desestimarse la infracción de los artículos lllsy 1.162 citados en los dos motivos del recurso [...]

${ }_{45}$ STS, Sala Primera de lo Civil, de fecha de 16 de noviembre de 1935: [...] De una manera eventual y accesoria pueden ser encomendadas a los abogados gestiones propias del contrato de mandato [...] en su esencia, los servicios de los letrados, como los de las demás personas que ejercen las profesiones liberales, no constituyen más que una modalidad, siquiera lo sea muya elevada y destacada, de lo que la tradición jurídica y nuestro Código Civil viene llamando contrato de arrendamiento de servicios [...]

${ }_{46}$ No obstante, en cuanto a las profesiones liberales en general, el Tribunal Supremo se inclina en favor de la teoría del arrendamiento de servicios tipificado en el artículo 1544 del Código Civil más adentrado el siglo XX. Así, la Sala Primera, de lo Civil, en Sentencia de fecha 18 de enero de 1941, establece que el contrato de arrendamiento de servicios resulta un molde amplísimo que cobija los servicios muy superiores y muy cualificados de quienes ejercen las llamadas profesiones y artes liberales. STS, Sala Primera de lo Civil, de fecha de 18 de enero de 1941: [...] El contrato de prestación o arrendamiento de servicios, molde amplísimo que cobija, sin género de duda, los servicios muy superiores o muy cualificados de quienes, como los Médicos, ejercen las llamadas profesiones y artes liberales, tiene como elementos esenciales la promesa de determinados servicios por una de las partes y la estipulación de una remuneración a cargo de la otra, la cual remuneración puede ser fijada por periodos de tiempo o por unidades de obra realizadas (piezas, medidas o actuaciones singulares) [...]

47 STS, Sala Primera de lo Civil, de fecha de 4 de febrero de 1950: [...] procede advertir que aunque de ordinario se presenta la relación contractual entre el letrado y el cliente como un contrato de servicios, también aparece otras como un contrato de obra, supuesto que se da cuando mediante remuneración, se obliga aquél a prestar no propiamente su actividad profesional, sino el resultado producido por la misma, lo cual ocurre, entre otros casos, en el de aceptar el letrado el encargo de emitir un dictamen [...]

(C) UNED. Revista de Derecho uned, núm. 27, 2021 
son encuadrables dentro del contrato de arrendamiento de servicios, también pueden someterse, en determinados supuestos, a la locatio conductio operis, cuando se obligan a prestar, no propiamente la actividad profesional, sino el resultado producido por la misma, como ocurre cuando aceptan el encargo de emitir dictámenes jurídicos ${ }^{48}$.

Traspasado el ecuador de la pasada centuria, en la Sentencia de fecha de 24 de enero de 1961, dictada en la Sala Primera de lo Civil, del Tribunal Supremo, se deja sentado, quizá con mayor rotundidad, que el contrato que configura un abogado con su cliente, para su defensa, es el de un arrendamiento de servicios, con independencia del modo en que se pacte la remuneración de los honorarios de aquél, que puede ser acordados a tanto alzado, sin guardar relación alguna con el tiempo empleado ${ }^{49}$. Así, el Tribunal Supremo vino sostiendo con relativa rotundidad que, en esencia, las relaciones jurídico-privadas que entablan los abogados deben ser encuadradas dentro del contrato de arrendamiento de servicios definido y tipificado en el artículo 1544 del Código Civil. ${ }^{50}$

Sin embargo, la Sala Primera, de lo Civil, del alto tribunal, en Sentencia de fecha de 6 de octubre de 1989, admite la posibilidad de resolución unilateral en el contrato entre un abogado y su cliente, por cualquiera de las partes, con aplicación de la regulación pro-

${ }^{48}$ A la misma conclusión llega la Sentencia dictada en la Sala de Primera, de lo Civil, en fecha de 28 de noviembre de 1984.

49 STS, Sala Primera de lo Civil, de fecha de 24 de enero de 1961: [...] Considerando que el problema planteado y resuelto en la sentencia objeto del presente recurso, no es otro que, presupuesta la existencia entre actor y demandado de un contrato verbal de arrendamiento de servicios profesionales mediante un precio alzado, hecho reconocido por ambas partes, determinar si la prestación de los servicios profesionales del demandado, Letrado en ejercicio, reguiada por dicho contrato, comprendía únicamente las consultas y asesoramientos extrajudiciales o alcanzaba también a la defensa en los pleitos de orden civil que mantuviera el actor ante los Tribunales de Justicia: Considerando que la sentencia objeto del presente recurso establece en el cuarto de sus considerandos, de un modo terminante, que valorando en su conjunto la prueba practicada en los autos, tanto la que expresamente señala o especifica, como la demás a que de modo genérico alude en la frase "y a las demás practicadas en las actuaciones» aparece a juicio de la Sala que el demandado [...] venía obligado por el contrato de arrendamiento de servicios que tenía concertado con el actor a defenderle en cuantos procedimientos se plantearan por él o contra él [...]

50 Serra Rodríguez cita una serie de Sentencias dictadas por el alto tribunal desde el año 1983 hasta el año 1998, en las que sostiene que la complejidad de la relación contractual de prestación de servicios entablada por el abogado no altera la naturaleza jurídica de la misma como arrendamiento de servicios. Entre otras, las STS, Sala Primera de lo Civil, de fechas de 6 de junio de 1983, de 17 de septiembre de 1983, 28 de noviembre de 1984, 7 de mayo de 1988, 15 de noviembre de 1996, 26 de mayo de 1997, 28 de enero de 1998 y 25 de junio de 1998. Vid. SERRA RODRÍGUEZ, A., La relación de servicios del abogado, op. cit., pág. 223. 
pia del mandato; si bien enmascara la aplicación de esta normativa bajo el pretendido carácter intuitu personae del arrendamiento de trabajo ${ }^{51}$. Además, la misma Sala del alto tribunal, en Sentencia de fecha de 11 de diciembre de 1990, afirma la irrelevancia de que se califique la relación contractual como mandato o arrendamiento de servicios, ya que siempre habrá de percibir precio el mandatario, arrendador o contratista ${ }^{52}$. Finalmente, el Tribunal Supremo, aunque inclinándose por la locatio conductio operarum, en Sentencia dictada en la Sala de lo Civil, en fecha de 22 de abril de 2013, con alusión a diversas resoluciones precedentes, establece que la relación contractual entre abogado y cliente se desenvuelve, normalmente, dentro de un contrato de gestión, que la propia jurispruden-

51 Vid. ALONSO PÉREZ, Ma .T., Los contratos de servicios de abogados, médicos y arquitectos, op. cit., pág. 130. STS, Sala Primera de lo Civil, de fecha de 6 de octubre de 1989: [...] si partimos de la base sentada por la Sala de Apelación de que el contrato que une a las partes es de arrendamiento de servicios, así como de la consideración acertadamente vertida por los órganos de instancia del carácter intuitu personae que ha de reconocerse a los servicios prestados por Letrados a sus clientes, basados primordialmente en la confianza que éstos depositan en aquéllos y que puede serles retirada en cualquier momento, sin que las normas colegiales impongan otro requisito para ello que el del abono previo de los prestados, no puede en modo alguno calificarse de ilógica la conclusión a que llega la resolución recurrida, que, tras de examinar las cláusulas del contrato, que interpreta correctamente, proclama la inadmisibilidad de la tesis sostenida por el actor de la necesaria duración indefinida y sine die del mismo y admite la de su resolución por voluntad de la demandada, a quien el actor prestó sus servicios profesionales, sin que ello suponga infracción de las normas que en los motivos que ahora se rechazan se citan como violados [...]. Además, Rodríguez Guitián entiende que el Tribunal Supremo, en Sentencia dictada en la Sala de lo Civil, en fecha de 28 de enero de 1998, deja sentado que las normas del contrato de mandato pueden integrar el contrato de arrendamiento servicios de los profesionales liberales, pero no porque se trate de una institución jurídica cuyo fundamento es la relación de confianza entre las partes, sino porque, al tener ambos como pilar básico la gestión, el primero de ellos es el contrato típico de gestión por excelencia; Vid. RODRÍGUEZ GUITIÁN, A.M ${ }^{\mathrm{a}}$., El desistimiento en el contrato de servicios de profesionales liberales, en Anuario de Derecho Civil, Vol. 54, N², Madrid, 2001, pág. 698.

${ }^{52}$ STS, Sala Primera de lo Civil, de fecha de 11 de diciembre de 1990: [...] la sentencia, al calificar el contrato de autos como contrato complejo, de naturaleza mixta, atipico y que presenta notas que le aproximan al arrendamiento de servicios y al manato [...] es absolutamente inane, irrelevante a efectos de la casación. Cualquiera que sea la naturaleza del contrato, mandato, arrendamiento de servicios, de obras, siempre habrá de percibir el precio el mandatario, arrendador o contratista, pero sólo el precio pactado y en la forma prevista en el contrato y, en todo caso, manteniendo el mandante, arrendatario o dueño de la obra, la posibilidad de desistir en cualquier momento, bien que sin perjuicio de indemnizar los beneficios dejados de obtener en caso de que el pacto tuviera duración o terminación previstas. Todos los contratos en que la relación es de algún modo "intuitu personae» permiten la resolución unilateral, como ya se ha dicho en jurisprudencia reiterada y conocida [...]

(C) UNED. Revista de Derecho uned, núm. 27, 2021 
cia construye con elementos tomados del arrendamiento de servicios $\mathrm{y}$ del mandato «de un modo no totalmente satisfactorio» ${ }^{53}$.

\section{LAS RELACIONES CONTRACTUALES DE SERVICIOS}

Es pacífico afirmar, como ha sido advertido, que las obligaciones que contraen los abogados con sus clientes, en el desempeño de las funciones propias de su profesión, son, por lo general, de medios o actividad, al no poder asociarse la prestación que realizan, en modo alguno, a la consecución del fin último perseguido por los segundos, beneficiarios del servicio. Así, resulta claro que el contrato que vincula a estos profesionales con sus clientes es, por lo común, de servicios. Ello, sin perjuicio de que, en determinados casos específicos, puedan quedar sometidos a la consecución del resultado perseguido, siendo entonces tal relación regida por un contrato de obra, como sucede, por ejemplo, en el supuesto de elaboración de un dictamen jurídico. Ahora bien, el problema radica en dilucidar cuál de los dos tipos contractuales civiles de servicios que se recogen en nuestro Código Civil, arrendamiento de servicios o mandato, resulta de aplicación a tales relaciones jurídico-privadas generadas en virtud de un contrato de servicios.

En nuestra opinión, tanto los argumentos ofrecidos por la doctrina mayoritaria para encajar los servicios prestados por los abogados dentro de la modalidad que la romanística denomina locatio con-

53 STS, Sala Primera de lo Civil, de fecha de 22 de abril de 2013: [...] La relación contractual existente entre abogado y cliente se desenvuelve normalmente en el marco de un contrato de gestión que la jurisprudencia construye, de modo no totalmente satisfactorio, con elementos tomados del arrendamiento de servicios y del mandato (SSTS de 28 de enero de 1998, 23 de mayo de 2006 y 27 de junio de 2006, 30 de marzo de 2006, RC n. ${ }^{\circ}$ 2001/1999, 14 de julio de 2005, RC n. ${ }^{\circ}$ 971/1999, 26 de febrero de 2007, RC $n .^{\circ} 715 / 2000,2$ de marzo de 2007, RC n. ${ }^{\circ} 1689 / 2000,21$ de junio de 2007, $R C$ n. ${ }^{\circ} 4486 / 2000,18$ de octubre de 2007, $R C$ n. ${ }^{\circ}$ 4086/2000, 22 de octubre de 2008, $R C n .^{\circ} 655 / 2003$ ) [...]. El mismo razonamiento es dado, de manera textual, en Sentencia de fecha de 6 de junio de 2018. Sin embargo, el alto tribunal, en reciente Sentencia dictada en la propia Sala de lo Civil, en fecha de 24 de febrero de 2020, vuelve a dar por su supuesto la aplicación del arrendamiento de servicios a las relaciones que nos ocupan. No obstante, y aunque esta última resolución verse sobre un conflicto de honorarios -expresión que, por cierto, emplea para referirse a la retribución, y no el de "salario"-, al pronunciarse en sus razonamientos jurídicos sobre el amparo que debe dar a los clientes la legislación relativa a consumidores o usuarios, dada su aplicación, a nuestro entender no puede darse por hecho tal encuadramiento, aunque tan sólo sea en virtud de la gran coincidencia que esta normativa sectorial presenta con el mandato a la hora de regular algunas previsiones esenciales, tal y como ocurre, por ejemplo, con la facultad de desistimiento unilateral sin justa causa que se otorga al propio beneficiario del servicio profesional. 
ductio operarum, que en nuestro ordenamiento jurídico se plasma en el artículo 1544 del Código Civil, como la tendencia jurisprudencial seguida desde los años veinte de la pasada centuria en el mismo sentido, adolecen de la consistencia jurídica que requiere la cuestión.

De una parte, parece que, para tal fin, desde cualquiera de los dos ámbitos, doctrinal y jurisprudencial, se centra la atención en ampliar los supuestos de prestación de servicios utilizando como fundamento esencial el que en los mismos cabe incluir tanto trabajos materiales como intelectuales. Sin embargo, hacen tabla rasa u obvian el contenido de lo regulado en los artículos 1583 a 1587 del Código Civil, que se refieren a los trabajos asalariados y, en última instancia, a todos aquellos que se caracterizan por ser mecánicos y manuales, lo que se deduce del propio espíritu de tales disposiciones. De otra parte, tanto la doctrina mayoritaria como la jurisprudencia, se dedican a buscar y ofrecer motivos por los que entienden que no es aplicable el mandato regulado en los artículos 1709 y siguientes del Código Civil, más que a profundizar en el por qué consideran aplicable el arrendamiento de servicios definido en el artículo 1544 de este cuerpo legal.

Alonso Pérez ${ }^{54}$, aun entendiendo que las relaciones civiles contractuales de los profesionales liberales pueden encajar en el concepto de locatio conductio operarum del artículo 1544 del Código Civil, toma mayor partido por la aplicación del contrato de mandato. En apoyo de tal postura, y en primer orden, argumenta: el mandato no sólo tiene por objeto la realización de actos jurídicos; el mandatario no está sometido a las instrucciones del mandante en un grado de intensidad del que pueda derivarse subordinación, o al menos que sea distinta a la de otro tipo de contratos civiles de trabajo; la representación no es un elemento esencial ni natural de este tipo contractual; la revocabilidad es una nota que, muy al contrario, induce a inferir la aplicación del mismo; y que no pueden tener cabida razonamientos sociológicos para rechazar su aplicación del mismo los supuestos que nos ocupan. Así, en segundo orden, concluye que la concepción como mandato de las relaciones contractuales que los profesionales liberales establecen con sus clientes es la que subyace en el Código Civil ${ }^{55}$.

${ }^{54}$ ALONSO PÉREZ, M 'T., Los contratos de servicios de abogados, médicos y arquitectos, op. cit., págs. 112-126 y págs. 162-165.

55 Ibidem. Si bien, la autora seguida sólo mantiene tal concepción respecto a los contratos de servicios propiamente dichos, no para los de obra. Razón que explica que los contratos de servicios propiamente dichos, tanto los onerosos como los gratuitos, así como los gratuitos de obra, se ubiquen en sede de mandato y, los onerosos de obra, en sede de arrendamiento. 
En el mismo sentido, Rodríguez Guitián ${ }^{56}$ aduce que es posible mantener que el codificador del siglo XIX regula las relaciones contractuales de servicios que establecen los profesionales liberales con sus clientes, en el desempeño de la actividad que le es propia, dentro de la normativa del mandato que se establece en el Código Civil, mientras que dentro del arrendamiento de servicios tan sólo se deja el trabajo manual retribuido. En apoyo de esta postura ofrece tres argumentos: en primer lugar, y como razón fundamental, afirma que el Código Civil reproduce el esquema romano de las relaciones de trabajo; en segundo lugar, opina que no puede atribuirse a un mero olvido del codificador el hecho de que en los artículos 1583 a 1587 del Código Civil no se haga mención alguna a los servicios de las profesiones liberales, ya que en otros preceptos si los nombra de forma expresa ${ }^{57}$; y, en tercer lugar, apunta que durante mucho tiempo se mantuvo en España el prejuicio romano de que el trabajo intelectual era superior al manual retribuido, de ahí que no resulte extraño que tal prejuicio se manifieste en que ambos tipos de trabajo se regulen por moldes contractuales distintos en el Código Civil.

Aunque en términos generales compartimos la práctica totalidad de los argumentos esgrimidos por ambas autoras en favor de la aplicación del mandato a las relaciones contractuales que establecen los profesionales liberales con sus clientes, en el desempeño de la actividad que le es propia, a nuestro entender es preciso ampliar y matizar algunos aspectos concretos en relación con la profesión de la abogacía -que incluso pueden ser aplicados a otras ocupaciones liberales-, al objeto de otorgar mayor consistencia al fin pretendido.

En lo que respecta al desistimiento ad nutum por parte del cliente, a lo regulado sobre la facultad de revocación del contrato por parte del mandante en los artículos 1733 y 1735 del Código Civil, que se centran, respectivamente, en el derecho que asiste a éste de revocar el mandato a su voluntad y en los supuestos de sustitución de mandatario, se ajustan preceptos de otras normas sectoriales que versan sobre la materia, las cuales deben integrar las relaciones jurídicas que subyacen entre el profesional, en este caso, el abogado, y el cliente. Así, el apartado 3 del artículo 62 de la Ley para la Defensa de Consumidores y Usuarios, Texto Refundido aprobado por

\footnotetext{
${ }^{56}$ RODRÍGUEZ GUITIÁN, A.M ${ }^{\mathrm{a}}$., El desistimiento en el contrato de servicios de profesionales liberales, op. cit., págs. 689-691.

57 Ibidem. Así, por ejemplo, en el artículo 1967 , ordinales $1^{\circ}$ y $2^{\circ}$, se establece el plazo de prescripción de tres años para las acciones al cumplimiento de las obligaciones contraídas con determinados profesionales liberales. Además, como señala la autora, no hay que obviar como en este precepto se utiliza el término "honorarios" en vez del de "salario".
} 
medio Real Decreto Legislativo 1/2007, de 16 de noviembre, para los supuestos de contratos de prestación de servicios o de suministros de tracto sucesivo o continuado, establece la prohibición de poner limitaciones que excluyan u obstaculicen el derecho del consumidor y usuario a poner fin a la relación ${ }^{58}$; desistimiento que podrá ejercer sin ningún tipo de sanción o de cargas onerosas o desproporcionadas, como la pérdida de las cantidades abonadas por adelantado. A su vez, el apartado 3 del artículo 68 del precitado Texto Refundido ${ }^{59}$ sienta que el derecho de desistimiento se regirá, en primer término, por las disposiciones legales que lo establezcan en cada caso, con lo que, sólo en defecto de regulación específica, será aplicable lo preceptuado al respecto en este cuerpo con rango y fuerza de ley ${ }^{60}$.

58 T.R.L.G.D.C.U. art. 62.3: En particular, en los contratos de prestación de servicios o suministro de productos de tracto sucesivo o continuado se prohíben las cláusulas que establezcan plazos de duración excesiva o limitaciones que excluyan u obstaculicen el derecho del consumidor y usuario a poner fin al contrato. El consumidor y usuario podrá ejercer su derecho a poner fin al contrato en la misma forma en que lo celebró, sin ningún tipo de sanción o de cargas onerosas o desproporcionadas, tales como la pérdida de las cantidades abonadas por adelantado, el abono de cantidades por servicios no prestados efectivamente, la ejecución unilateral de las cláusulas penales que se hubieran fijado contractualmente o la fijación de indemnizaciones que no se correspondan con los daños efectivamente causados.

${ }_{59}$ T.R.L.G.D.C.U. art. 68.3: El derecho de desistimiento atribuido legalmente al consumidor y usuario se regirá en primer término por las disposiciones legales que lo establezcan en cada caso y en su defecto por lo dispuesto en este Título.

${ }^{60}$ BELUCHE RINCÓN, I., El contrato de servicios. El derecho del cliente a desistir de forma unilateral, en Revista de Derecho Civil, Vol. II, N 2 (abril-junio), Madrid, 2015, págs. 87-89. Según sostiene esta autora, el singular derecho que faculta al cliente a desvincularse del contrato durante un brevísimo período de tiempo posterior a su perfección -establecido en el apartado 1 del artículo 71 de la vigente Ley para la Defensa de los Consumidores y Usuarios de 2007 (14 días naturales) y en otras leyes especiales-, que encuentra su razón de ser en la necesidad de protección del usuario, es una institución con un fundamento y una lógica que en poco se aproxima al derecho de desistimiento unilateral de la Teoría General. En tal sentido, la autora opina que la idéntica nomenclatura conduce a una clara confusión de ambas figuras -que, según ella misma, podría haberse evitado denominando a la facultad del usuario "derecho de arrepentimiento"-, cuyas diferencias, a grosso modo, son numerosas. En virtud de ello, la propia autora citada concluye que, de tratarse de contratos en los que se atribuya al consumidor el singular derecho a desistir, éste podrá ejercitarlo en el breve periodo establecido al efecto o, de omitir su ejercicio, nada le impide -si es que goza de tal facultad-poder desistir ad nutum con posterioridad a la relación contractual, como es el caso de los contratos de prestación de servicios o suministro de bienes de tracto sucesivo reflejados en el artículo 62 del Texto Refundido de la Ley de Consumidores y Usuarios de 2007, transcrito en parte anteriormente. Es decir, conforme a este criterio, el cliente-consumidor podrá desistir unilateralmente, bien dentro del plazo de los catorce días siguientes a la celebración del contrato de servicios con su abogado, bien con posterioridad, en virtud de lo establecido en el artículo 1733 del Código Civil.

(C) UNED. Revista de Derecho uned, núm. 27, 2021 
Pues bien, el Estatuto General de la Abogacía Española, aprobado por medio de Real Decreto 658/2001, de 22 junio, en su artículo 26, apartados 2 y 3 , preceptúa que el abogado que haya de encargarse de la dirección profesional de un asunto, que previamente se hubiere encomendado a otro, deberá solicitar su venia, con carácter previo y por escrito, y, en todo caso, recabar del mismo la información necesaria para continuar el asunto, sin que tal petición pueda denegarse por parte del abogado sustituido, estando obligado a devolver la documentación que obre en su poder y a facilitar al nuevo letrado la información necesaria para continuar la defensa ${ }^{61}$.

Es evidente que la sustitución del letrado al que se le encomendó un determinado asunto puede producirse en cualquier momento, dado que nada se dice sobre la existencia de un plazo determinado. $\mathrm{Al}$ punto, resulta notorio que dicha resolución unilateral trae causa directa de una decisión sobrevenida y adoptada por el cliente respecto a que dicho abogado sustituido continúe ocupándose de su asistencia o defensa técnica, revocando el contrato que les vinculaba; desistimiento que puede ser ad nutum, sin alegar justa causa. En definitiva, el cliente, beneficiario del servicio, o interesado en el mismo, puede renunciar en cualquier momento del proceso a la asistencia o defensa técnica del abogado y sustituirlo por otro. Por tanto, dado que el artículo 1733 del Código Civil incluye la facultad que posee el mandante (cliente) de revocar el mandato a su voluntad y ad nutum $^{62}$, así como el artículo 1735 del Código Civil dispone que el nombramiento de un nuevo mandatario (abogado sustituto) supondrá el cese del anterior (abogado sustituido), desde el momento en que se le comunica tal situación, con la revocación de la relación jurídica preexistente ${ }^{6363}$, la normativa sectorial aludida con anterioridad es en alto grado acorde a la regulación que sobre la figura del desistimiento unilateral, sin justa causa, se realiza en sede de man-

${ }^{61}$ E.G.A.E. art. 26.2-3: 2. Los abogados que hayan de encargarse de la dirección profesional de un asunto encomendado a otro compañero en la misma instancia deberán solicitar su venia, salvo que exista renuncia escrita e incondicionada a proseguir su intervención por parte del anterior letrado, y en todo caso, recabar del mismo la información necesaria para continuar el asunto. 3. La venia, excepto caso de urgencia a justificar, deberá ser solicitada con carácter previo y por escrito, sin que el letrado requerido pueda denegarla y con la obligación por su parte de devolver la documentación en su poder y facilitar al nuevo letrado la información necesaria para continuar la defensa.

${ }_{62}$ C.C. art. 1733: El mandante puede revocar el mandato a su voluntad, y compeler al mandatario a la devolución del documento en que conste el mandato. Es evidente que el artículo también engloba la revocación del mandato con justa causa.

63 C.C. art. 1735: El nombramiento de nuevo mandatario para el mismo negocio produce la revocación del mandato anterior desde el día en que se hizo saber al que lo había recibido, salvo lo dispuesto en el artículo que precede. 
dato por nuestro Código Civil. Ello supone un argumento a añadir para cimentar con mayor fuerza la ubicación de la prestación de servicios de los letrados dentro de este tipo contractual.

Además, tanto en el ámbito procesal como en el extrapocesal, la renuncia o desistimiento ad nutum del cliente faculta al abogado para reclamar los honorarios correspondientes a su intervención ${ }^{64}$, así como los gastos que le hubiere producido la realización del encargo $^{65}$ y la indemnización por los daños irrogados en el cumplimiento del mismo, si se hubieren producido sin haber incurrido el profesional en culpa o imprudencia. En fin, resulta palmario que, de la regulación que de estos parámetros se hace en las normas sectoriales que rigen la actividad de la abogacía y, en última instancia, de la aplicación de usos y constumbres de la profesión, es deducible también un alto grado de concordancia con lo dispuesto sobre el particular en sede de mandato por nuestro Código Civil, respecto a los derechos del mandatario para los supuestos de extinción del contrato que le vincula ${ }^{66}$.

En lo que respecta al desistimiento por parte del abogado, tanto ad nutum como con justa causa, las normas sectoriales reguladoras de la profesión que prevén tales extinciones unilaterales también se ajustan en alto grado a la normativa reguladora sobre el particular contenida en sede de mandato (artículos 1736 y 1737 del Código Civil). Así, en el apartado 1 del artículo 26 del Estatuto General de la

${ }^{64}$ E.G.A.E. art. 26.4: El letrado sustituido tendrá derecho a reclamar los honorarios que correspondan a su intervención profesional y el sustituto tendrá el deber de colaborar diligentemente en la gestión de su pago.

${ }^{65}$ E.G.A.E. art. 44.1: El abogado tiene derecho a una compensación económica adecuada por los servicios prestados, así como al reintegro de los gastos que se le hayan causado. La cuantía de los honorarios será libremente convenida entre el cliente y el abogado, con respeto a las normas deontológicas y sobre competencia desleal. A falta de pacto expreso en contrario, para la fijación de los honorarios se podrán tener en cuenta, como referencia, los baremos orientadores del Colegio en cuyo ámbito actúe, aplicados conforme a las reglas, usos y costumbres del mismo, normas que, en todo caso, tendrán carácter supletorio de lo convenido y que se aplicarán en los casos de condena en costas a la parte contraria. El vigente Código Deontológico de la Abogacía Española (C.D.A.E.), aprobado por el Pleno del Consejo General, en fecha de 6 de marzo de 2019, en su artículo 14, apartado 1, establece el derecho del abogado a "percibir retribución u honorarios por su actuación profesional, así como el reintegro de los gastos que se le hayan causado".

${ }^{66}$ C.C. art. 1728.2-3: 2. Si el mandatario las hubiera anticipado, debe reembolsarlas el mandante, aunque el negocio no haya salido bien, con tal que esté exento de culpa el mandatario. 3. El reembolso comprenderá los intereses de la cantidad anticipada, a contar desde el día en que se hizo la anticipación. C.C. art. 1729: Debe también el mandante indemnizar al mandatario de todos los daños y perjuicios que le haya causado el cumplimiento del mandato, sin culpa ni imprudencia del mismo mandatario.

(C) UNED. Revista de Derecho uned, núm. 27, 2021 
Abogacía Española ${ }^{67}$, se establece que todo abogado tendrá plena libertad de aceptar o rechazar la dirección del asunto que se le pretenda encomendar, así como de renunciar al mismo en cualquier fase del procedimiento, pero siempre que con ello no se genere indefensión al cliente. Entendemos que cabe, sin duda alguna, el desistimiento ad nutum del abogado en el contrato de prestación de servicios y en cualquier momento del proceso ${ }^{68}$, salvo en el supuesto en el que efectúe una renuncia unilateral prácticamente in extremis, dentro de un breve espacio temporal previo a la celebración de actos de juicio o vista orales señalados, en el que se le coerce, bajo pena de sanción disciplinaria judicial, con el deber de alegar justa causa ${ }^{69}$.

Con carácter ordinario, el abogado está facultado para desistir, ad nutum o con justa causa, del contrato de servicios que le vincula a su cliente -salvo en determinados casos específicos y concretos, como en los supuestos de asistencia jurídica gratuita ${ }^{70}-$. Tal desis-

67 E.G.A.E. art. 26.1: Los abogados tendrán plena libertad de aceptar o rechazar la dirección del asunto, así como de renunciar al mismo en cualquier fase del procedimiento, siempre que no se produzca indefensión al cliente.

68 El Tribunal Supremo, Sala Primera de lo Civil, en Auto de fecha de 4 de marzo de 2008, aunque en obiter dicta, reconoce la facultad que ostenta el abogado de desistir unilateralmente y ad nutum en la asistencia o defensa técnica de su cliente, con el único límite de no provocarle indefensión. Es preciso resaltar que el alto tribunal apenas ha llegado a emitir pronunciamiento respecto la renuncia del abogado, en cuanto a la sustantividad de la misma ni a sus efectos contractuales. ATS, Sala Primera de lo Civil, de fecha de 4 de marzo de 2008: [...] se hace preciso recordar al impugnante en reposición que, si bien es cierto la renuncia a la condición de representante letrado no está sujeta a condición-salvo que produjera indefensión al cliente- [...]

${ }^{69}$ La Ley 6/1985, de 1 de julio, Orgánica del Poder Judicial, únicamente se refiere a la renuncia en su Título V, del Libro VII, que regula las sanciones que pueden imponerse a los que intervienen en los pleitos o causas y, en ordinal $4^{\circ}$ de su artículo 553, establece que, tanto los abogados, como los procuradores, serán también corregidos disciplinariamente "cuando renuncien injustificadamente a la defensa o representación que ejerzan en un proceso, dentro de los siete días anteriores a la celebración del juicio o vistas señaladas". A través de este precepto, aparte de pretender evitar cualquier tipo de dilación indebida del procedimiento, se persigue la no indefensión del justiciable, así como, dado el escaso margen de tiempo, el no crearles perjuicio alguno al respecto. El precepto concuerda con lo previsto en el artículo 1736 del Código Civil para evitar perjuicios al mandante

70 Según lo dispuesto en el artículo 31 de la Ley 1/1996, de 10 de enero, de Asistencia Jurídica Gratuita, los abogados designados de oficio desempeñarán sus funciones, de manera real y efectiva, hasta la terminación del proceso en la instancia judicial de que se trate y, en su caso, la ejecución de las sentencias, si las actuaciones procesales en ésta se produjeran dentro de los dos años siguientes a la resolución judicial dictada en la instancia. Sólo en el orden penal podrán los abogados designados excusarse de la defensa. Para ello deberá concurrir un motivo personal y justo, que será apreciado por los Decanos de los colegios. Por tanto, fuera del orden penal, los abogados designados de oficio no pueden excusarse de la defensa y, 
timiento es acorde al regulado en los artículos 1736 y 1737 del Código Civil. El primero de los artículos citados concede al mandatario la facultad de renunciar al encargo encomendado, por su propia voluntad, con o sin justa causa ${ }^{71}$. El segundo, establece que, tanto en los supuestos de renuncia ad nutum como cuando se invoque justa causa, el mandatario debe continuar su gestión hasta que el mandante haya podido tomar las disposiciones necesarias para ocurrir a esta falta ${ }^{72}$, lo que concuerda con la condición impuesta en el precitado apartado 1 del artículo 26 del Estatuto General de la Abogacía Española, es decir, con la premisa de que el desistimiento no produzca indefensión al cliente.

En nuestra opinión, el régimen regulado en los artículos de nuestro Código Civil reseñados en el párrafo precedente alberga distintos supuestos de hecho. En primer lugar, concede al mandatario la facultad de renunciar al encargo encomendado, tanto ad nutum, como argumentando justa causa. En segundo lugar, se alude al supuesto en el que el mandatario, con motivo de su renuncia, genere al mandante algún tipo de daño o perjuicio, lo que se producirá siempre que el primero cese en la realización de la prestación sin haber dado la oportunidad al segundo de tomar las disposiciones necesarias para sustituirlo u ocurrir a su falta, o, de haber dado tal oportunidad, no hubiere podido el cliente valerse de otra persona o cubrir su ausencia, por causas ajenas a su voluntad o de fuerza mayor, para la materialización del objeto del mandato. Finalmente, la renuncia del mandatario no será indemnizable siempre que la misma traiga causa de sobrevenir imposibilidad real o legal de realización del encargo encomendado ${ }^{73}$. A su vez, es preciso añadir que el carácter

únicamente, en caso de que consideren insostenible la pretensión o consideren insuficiente la documentación aportada para evaluar la pretensión, deben actuar conforme a lo previsto en el artículo 32 de la precitada Ley. El letrado ha de seguir ejerciendo la defensa técnica conferida incluso cuando solicite su baja en el turno de oficio. Vid. FERNÁNDEZ GALIARDO, J.A., La renuncia de procuradores y abogados a su representación y defensa técnica, en Revista Jurídica de la Universidad Autónoma de Madrid, $\mathrm{N}^{\mathrm{o}}$ 29, Madrid, 2014, págs. 111-112.

${ }^{71}$ C.C. art. 1736: El mandatario puede renunciar al mandato poniéndolo en conocimiento del mandante. Si éste sufriere perjuicios por la renuncia, deberá indemnizarle de ellos el mandatario, a menos que funde su renuncia en la imposibilidad de continuar desempeñando el mandato sin grave detrimento suyo.

72 C.C. art. 1737: El mandatario, aunque renuncie al mandato con justa causa, debe continuar su gestión hasta que el mandante haya podido tomar las disposiciones necesarias para ocurrir a esta falta.

${ }^{73}$ Como sucede, por ejemplo, cuando concurren las circunstancias que afecten a la libertad, independencia y secreto profesional establecidas en el apartado 5 del artículo 12.A. del vigente Código Deontológico de la Abogacía Española, aprobado por el Pleno del Consejo General de la Abogacía Española, en fecha de 6 de marzo de

(C) UNED. Revista de Derecho uned, núm. 27, 2021 
gratuito $\mathrm{u}$ oneroso del mandato de que se trate no influye en absoluto en la cuestión que nos ocupa, dado que las normas que regulan tal tipo contractual están previstas para ambos supuestos, en virtud de lo establecido en el artículo 1711 del Código Civil ${ }^{74}$.

En otro orden de cosas, el hecho de valorar y respetar socialmente de igual manera a todas las profesiones $\mathrm{u}$ oficios, $\mathrm{o}$, mejor dicho, tanto a las personas que se dedican al ejercicio de trabajos materiales como a los que desempeñan actividades de carga sustancialmente intelectual, no preestablece, por tal motivo, que se desestime por completo la aplicación del esquema contractual del mandato a todo tipo de prestación de servicios. Y es que, si bien es cierto que desde la Roma clásica se encuadran dentro del mandato a las relaciones que establecen los profesionales liberales con sus clientes, utilizando para ello como fundamento la mayor consideración social que ostentan los que se dedicaban a esta clase de actividades, no es menos cierto que en dicha ubicación también influyen otros factores, como el alto grado de autonomía, independencia y libertad, características ínsitas en tales actividades, que hacen imposible la aplicación de la locatio conductio y sí la de un tipo contractual que sea compatible con dichas notas esenciales y que sea naturalmente retribuido en esos supuestos, bajo el concepto honorarium ${ }^{75}$.

2019. En estos supuestos el letrado deberá cesar obligatoriamente en su asistencia o defensa técnica.

${ }^{74}$ Del contenido íntegro de los artículos 1736 y 1737 del Código Civil, algunos autores deducen la imposibilidad de aplicar el régimen de renuncia del mandato a la relación entre abogado y cliente. Entre ellos, Gabriel Macanás, quien sostiene que la propia dinámica de la renuncia en sede de mandato lleva a determinar que la misma no es libre ni irresponsable, dado que el propio régimen establecido en los precitados artículos 1736 y 1737, puestos en relación con lo dispuesto en los artículos 1732 y 1718 , parte de la premisa de la gratuidad, lo que condiciona las consecuencias establecidas. Así, este autor señala que al mandatario se le otorga tal facultad de extinción unilateral del contrato, pero de forma responsable y, por ende, resarcitoria, salvo que fuera prevalente la indemnidad de este interviniente frente a la del mandante ("a menos que funde su renuncia en la imposibilidad de continuar desempeñando el mandato sin grave detrimento suyo"), preponderancia que sólo se comprende si se tratare de actuaciones gratuitas. Vid. GABRIEL MACANÁS, V., La renuncia del abogado en el contrato de servicios: Incumplimiento contractual e irrelevancia procesal, en in Dret. Revista para el análisis del Derecho, $\mathrm{N}^{\circ} 3$, Barcelona, 2015, págs. 19-20.

${ }_{75}$ El proyecto de Código Civil de 1851, en el que se definía al mandato como esencialmente gratuito en su artículo 1602, no seguía la tradición romanística en sentido estricto, mas, sin embargo, el Código Civil de 1889 sí da continuidad a la misma, al introducir la presunción de onerosidad de este tipo contractual cuando los mandatarios se dediquen a la profesión relacionada con la prestación objeto de dicha relación contractual, por medio del artículo 1711. Además, el propio García Goyena, aunque considerase el mandato en el artículo 1602 del proyecto de Código Civil de 1851 como esencialmente gratuito, apunta ya en ese momento que no 
En cuanto a la nota de independencia, incluso mostrando nuestra conformidad respecto a que el grado de dependencia, con relevancia jurídica, es prácticamente el mismo en todos los contratos civiles de trabajo, no es menos cierto que, en última instancia, ha de entenderse que en el mandato la misma se da en menor medida que en el resto, debido precisamente a lo establecido en los artículos 1715 y 1719 del Código Civil. Estas disposiciones refieren, respectivamente, a que no se consideran traspasados los límites del mandato si en su ejecución se obtiene un resultado más ventajoso para el mandante ${ }^{76} \mathrm{y}$ a la posibilidad de que este contrato se perfeccione y realice sin instrucciones dadas al mandatario ${ }^{77}$.

A todo ello es necesario añadir que la definición dada en el artículo 1544 del Código Civil otorga carácter esencial a la contraprestación del que contrata el servicio del profesional, por lo que no da cabida alguna a la prestación gratuita, posibilidad que sí cobija el mandato en la primera parte del artículo 1711 del mismo cuerpo legal. Cabría pensar que el escollo de la esencialidad del precio se salva aduciendo el general carácter dispositivo de la norma sustantiva en el ámbito Civil, mas, sin embargo, no puede deducirse tal carácter del contenido del precitado artículo 1544, ya que, como se ha advertido, se trata de una definición, por lo que excluir la onerosidad del mismo supondría desnaturalizar por completo la locatio conductio operarum que acoge ${ }^{78}$. Por otro lado, en el caso del man-

se puede llamar arriendo al contrato de un abogado con su cliente o al de un doctor con su paciente, dado que se trata de actividades en las que, por su decoro o vanidad, no se puede denominar más que como honorarium a la remuneración que éstos perciben por la realización de su trabajo, por lo que, algunos califican de mandato al primer caso y de contrato innominado al segundo. Es decir, el jurista valora en su proyecto de código la necesidad de aplicar el mandato a las relaciones jurídico-privadas que entablen los profesionales liberales con sus clientes, en el ejercicio de la actividad que le es propia. Vid. GARCÍA GOYENA, F., Concordancias, motivos y comentarios del Código Civil Español, Edit. Rase, Barcelona, 1973, págs. 54-56.

76 C.C. art. 1715: No se consideran traspasados los limites del mandato si fuese cumplido de una manera más ventajosa para el mandante que la señalada por éste.

77 C.C. art. 1719: En la ejecución del mandato ha de arreglarse el mandatario a las instrucciones del mandante. A falta de ellas, hará todo lo que, según la naturaleza del negocio, haría un buen padre de familia.

${ }^{78}$ En última instancia, y en nuestra opinión cabría ampliar la aplicación del arrendamiento de servicios, en virtud de una interpretación extensiva, a todos aquellos oficios o profesiones en los que prime su contenido material, manual o mecánico, que, no siendo asalariados -que entrarían en el ámbito laboral-, se realicen de manera autónoma, siempre que sean onerosos, en los que, debido a su complejidad o a un contexto adverso determinado, no se pueda asegurar en su cumplimiento la consecución de un resultado favorable, como puede suceder, por ejemplo, en cualquier tipo de instalación que resulte complicada (eléctrica, mecánica, etc.). Y es que, en este sentido, entendemos la regulación contenida en los artículos

(C) UNED. Revista de Derecho uned, núm. 27, 2021 
dato, aun aplicándose directamente la presunción de onerosidad establecida en la segunda parte del artículo 1711, la misma puede ser excluida por pacto en contrario.

\section{EL SOMETIMIENTO A UNA OBLIGACIÓN DE RESULTADO}

Es evidente que ciertas actuaciones de los letrados pueden quedar vinculadas a la consecución de un resultado, por lo que ha de quedar sometidas a la regulación de los que denominamos contratos de obra. Por ejemplo, cabe destacar el supuesto en que un abogado se compromete a elaborar un informe o dictamen jurídico sobre una determinada cuestión ${ }^{79}$. Otros supuestos de contratos de obra se dan cuando el abogado se compromete a la elaboración de determinados documentos, como, por ejemplo, la redacción de un contrato o de unos estatutos de una sociedad.

Sentado lo anterior, y en nuestra opinión, cabe perfectamente la aplicación del contrato de mandato a las relaciones jurídico-privadas que entablan los abogados con sus clientes, en el desempeño de la actividad que le es propia, cuando el encargo asumido por el primero suponga la realización efectiva del fin último perseguido por el segundo. Al tenor de la definición contenida en el artículo 1709 del Código Civil, al amparo de la expresión "hacer alguna cosa" cabe incluir la ejecución de cualquier tipo o especie de obra, tanto de carácter intelectual como material. Como es sabido, el contenido del precitado artículo hay que ponerlo en relación con la presunción de onerosidad consagrada en el artículo 1711 del Código Civil, en relación a todos los mandatarios que tengan por ocupación o profesión el desempeño

1583 a 1587 del Código Civil tiene, en su espíritu, vocación de amparar tan sólo trabajos de carácter material, tal y como se desprende de lo dispuesto en los artículos 1584, 1586 y1587, al referirse a "criados domésticos", "criados de labranza", "menestrales" y "artesanos". Ello con mayor razón aún al momento actual, si tenemos en cuenta que los trabajadores "asalariados", concepto en el que pueden caber todo tipo de actividades, tanto materiales como intelectuales, quedan sometidos al ámbito del Derecho del Trabajo.

79 STS, Sala Primera de lo Civil, de fecha de 4 de febrero de 1950: [...] y como complemento de está doctrina procede advertir que aunque de ordinario se presenta la relación contractual entre el Letrado y su cliente como un contrato de servicios, también aparece otras veces como contrato de obra, supuesto que se da cuando mediante remuneración se obliga a aquél a prestar no propiamente su actividad profesional, sino el resultado producido por la misma, cual ocurre, entre otros casos, en el de aceptar el Letrado el encargo de emitir un dictamen [...]. El alto tribunal, en Sentencia de 4 de octubre de 1905, ya había calificado como contrato de obra el supuesto en el que un abogado se compromete a la elaboración de un dictamen jurídico. 
del servicio o encargo de la especie a que se refiera el mandato; onerosidad que puede ser excluida por medio de pacto en contrario.

No obstante, es posible defender los postulados sostenidos por Alonso Pérez ${ }^{80}$ y encajar en el arrendamiento de obra las relaciones jurídicas onerosas por las que un abogado queda comprometido con su cliente a la consecución de un resultado determinado, con fundamento en el principio lex especialis derogat legi generali, por dos razones. La primera de ellas se fundamenta en el hecho de que, al contrario de lo que sucede en la regulación contenida para el arrendamiento de servicios en los artículos 1583 a 1587 del Código Civil, del espíritu de los artículos 1588 a 1600 de este cuerpo legal no puede deducirse, en modo alguno, la vocación de abordar tan sólo los trabajos de índole material, al punto que no se refiere tampoco a relaciones asalariadas, por lo que su aplicación se ajusta de manera suficiente a la características intrínsecas y esenciales que definen a las profesiones liberales y a la dinámica del ejercicio forense de las mismas. La segunda, porque incluso en uno de dichos artículos, el $1593^{81}$, se nombra expresamente al arquitecto, motivo por el que se puede entender la vocación de ampliar la regulación al resto de profesiones liberales ${ }^{82}$.

${ }^{80}$ Según Alonso Pérez, las relaciones profesionales que obligan a la consecución de un determinado resultado, pueden entenderse regidas tanto por lo dispuesto en los artículos 1544 y 1588 a 1600, como por lo definido y regulado en los artículos 1709 y siguientes del Código Civil. Pero, la autora afirma que este concurso de normas puede despejarse si se atiende al dato de que los artículos 1709 y siguientes del Código Civil se refieren a relaciones onerosas y gratuitas, bien de servicios propiamente dichos, bien de obra, mientras que en los artículos 1588 a 1600 de dicho cuerpo legal tan sólo habla de relaciones onerosas de obra. Cfr. ALONSO PÉREZ, $\mathrm{M}^{\mathrm{a}}$.T., Los contratos de servicios de abogados, médicos y arquitectos, op. cit., 129.

81 C.C. art. 1593: El arquitecto o contratista que se encarga por un ajuste alzado de la construcción de un edificio u otra obra en vista de un plano convenido con el propietario del suelo, no puede pedir aumento de precio aunque se haya aumentado el de los jornales o materiales; pero podrá hacerlo cuando se haya hecho algún cambio en el plano que produzca aumento de obra, siempre que hubiese dado su autorización el propietario.

82 Sin embargo, puede encontrarse un obstáculo a la aplicación de este criterio. Así, en tal sentido, es preciso resaltar que la regulación del arrendamiento de obra tan sólo refiere al desistimiento ad nutum por parte del comitente o cliente (artículo 1594 del Código Civil), sin aludir la regulación en momento alguno al profesional liberal. Mas, no cabe la menor duda que, al nada decirse en tal sentido acerca de la renuncia del profesional liberal, en última instancia cabría perfectamente la aplicación analógica de la normativa del mandato al respecto. Conforme a lo dispuesto en el artículo 1594 del Código Civil, el cliente -el comitente- puede desistir, a su propia conveniencia, aunque la obra haya empezado, pero debiendo indemnizar al que la ejecuta por los gastos, el trabajo realizado y la utilidad que le hubiere reportado la misma. En nuestra opinión, y tan sólo en lo que respecta a las profesiones liberales, fundadas en relaciones de confianza, intuitu personae, así como dadas sus pecu-

(C) UNED. Revista de Derecho uned, núm. 27, 2021 


\section{CONCLUSIONES}

En primer orden, a nuestro entender actualmente resulta palmario deducir que el mandato no sólo tiene por objeto la realización de actos jurídicos, que puede ser retribuido, que el mandatario no está sometido a las instrucciones del mandante en un grado de intensidad del que pueda derivarse subordinación, que la representación no se erige en su elemento esencial ni natural y que no pueden tener cabida argumentos sociológicos para rechazar la aplicación del mismo a los supuestos que nos ocupan. Estos factores ya de por sí pueden llevar a determinar la aplicación, con carácter ordinario, del mandato a las relaciones jurídico-privadas que establecen los abogados con sus clientes, en el ejercicio de la actividad que le es propia.

En segundo orden, y además, de parámetros como la facultad de revocación, sin justa causa, del cliente/mandante, la renuncia, con o sin justa causa, del abogado/mandatario, la mayor autonomía y, por ende, independencia y libertad, que han de ostentar el prestador del servicio y el carácter esencial de onerosidad que define a la locatio conductio operarum, sólo cabe deducir, en nuestra opinión, que las relaciones que nos ocupan deben ubicarse dentro del contrato de mandato, definido y regulado en sus artículos 1709 y siguientes del Código Civil. Y ello tanto si se trata de una prestación de servicios stricto sensu (obligación de medios) como si se trata de supuestos extraordinarios y concretos de realización de una obra (obligación de resultado), y sean todas esas relaciones onerosas o gratuitas. No obstante, en aquellos supuestos, extraordinarios y onerosos, en los que el abogado queda compelido a la consecución de un determinado resultado, es posible defender la aplicación del arrendamiento de obra, en virtud del principio lex especialis derogat legi generali.

\footnotetext{
liares características, en la práctica no cabrá más que abonar por parte del cliente el trabajo realizado hasta el momento del desistimiento, así como los gastos que la ejecución del encargo le haya producido, sin que quepa indemnizar por la utilidad que le hubiera reportado la obra, salvo que la revocación del contrato se haya producido en un estadio o en unas circunstancias que traigan graves consecuencias a este último. Piénsese, por ejemplo, en el caso de un abogado al que se le encarga un dictamen jurídico, el desistimiento del comitente tan sólo puede traer como consecuencia la remuneración del trabajo realmente ejecutado y el reintegro de los gastos ocasionados para su realización, pero no la utilidad que le pudiere proporcionar el encargo, salvo que, para ello, por la complejidad del trabajo, hubiere tenido que renunciar a atender otros encargos, con una dedicación cuasi exclusiva.
} 


\section{BIBLIOGRAFÍA}

Agudo Ruiz, A., Abogacía y abogados, un estudio histórico-jurídico, Edit. Egido Editorial, Zaragoza.

Albaladejo García, M., Derecho Civil. Derecho de obligaciones, Vol. II, Tomo II, Edit. Librería Bosch, Barcelona, 2002.

Alonso PÉrez, M ${ }^{\mathrm{a}}$.T., Los contratos de servicios de abogados, médicos y arquitectos, Edit. J.M. Bosch Editor, Barcelona, 1997.

Bartol Hernández, F., Errores en el Codex Florentinus, en Revista de estudios histórico-jurídicos, $\mathrm{N}^{\mathrm{o}}$ 36, Valparaiso (Chile), 2014.

Beluche Rincón, I., El contrato de servicios. El derecho del cliente a desistir de forma unilateral, en Revista de Derecho Civil, Vol. II, N ${ }^{\circ}$ 2 (abril-junio), Madrid, 2015.

Blanco PÉrez-Rubio, L., Obligaciones de medios y obligaciones de resultado. ¿Tiene relevancia jurídica su distinción?, en Cuaderno de Derecho Transnacional, Vol. 6, N 2, Madrid, 2014.

Mosset IturRaspe, J., Responsabilidad civil del médico, Edit. Astrea, Buenos Aires, 1979.

Ataz LÓpez, J., Los médicos y la responsabilidad civil, Edit. Montecorvo, Madrid, 1985.

De la Quintana Ferguson, M., La responsabilidad civil del médico, Edit. Estades, Artes Gráficas, Madrid, 1949.

Demogue, R., Traité des Obligations en Général, Tomo V, Edit. Rousseau \& Cie, París, 1923.

De Robertis, F., I rapporti di lavoro nel Diritto Romano, Edit. Dott. A. Giuffrè Editore, Milano, 1946.

D’Ors, A., Elementos de Derecho Privado Romano, Edit. EUNSA, Pamplona, 2006.

Fernández De Buján, A., El abogado en Roma, en Historia de la Abogacía Española, Vol. I, Edit. Thomson Reuters Aranzadi, Pamplona, 2015.

Fernández De Buján, F., Sistema contractual romano, Edit. Dykinson, Madrid, 2004.

FERNÁNDEZ GALIARDO, J.A., La renuncia de procuradores y abogados a su representación y defensa técnica, en Revista Jurídica de la Universidad Autónoma de Madrid, № 29, Madrid, 2014. 
Fernández Hierro, J.M., Sistema de responsabilidad médica, Edit. Comares, Granada, 1997.

Gabriel Macanás, V., La renuncia del abogado en el contrato de servicios: Incumplimiento contractual e irrelevancia procesal, en in Dret. Revista para el análisis del Derecho, N 3, Barcelona, 2015.

García Garrido, M.J., Derecho Privado Romano. Casos-acciones-instituciones, Edit. Ediciones Académicas, Madrid, 2015.

García Goyena, F., Concordancias, motivos y comentarios del Código Civil Español, Edit. Rase, Barcelona, 1973.

Gitrama González, M., Configuración jurídica de los servicios médicos, en Estudios de Derecho Público y Privado ofrecidos al profesor Serrano y Serrano, Edit. Universidad de Valladolid, 1965.

GÓmez-Iglesias Casal, A., La influencia del Derecho Romano en las modernas relaciones de trabajo, Edit. Civitas, Madrid, 1995.

Kasser, M., Derecho Privado Romano, trad. por Santa CRUZ TEJERIZO, J., Edit. Reus, Madrid, 1982.

Lacruz Berdejo, J.L. (Y OTROS), Derecho de obligaciones. Contratos y cuasicontratos. Delitos y cuasidelitos, Tomo II, Vol. Segundo, Edit. Bosch, Barcelona, 1995.

Lasarte Álvarez, C., Principios de Derecho Civil. Contratos, Tomo III, Edit. Marcial Pons, Madrid, 2003.

Lenel, O., La esencia del mandato, en Revista de Derecho Privado, Madrid, 1944.

Llamas Pombo, E., La responsabilidad civil del médico, aspectos generales y modernos, Edit. Trivium, Madrid, 1988.

Loвато GÓmez, J.M., Contribución al estudio de la distinción entre las obligaciones de medios y las obligaciones de resultado, en Anuario de Derecho Civil, Vol. 45, N 2, Madrid, 1992.

Martín MinguiJón, A.R., Acciones ficticias y acciones adyeticias, Edit. Dykinson, Madrid, 2001.

Martini, R., Mercennarius, contributo allo studio dei rapporti di lavoro in Diritto Romano, Edit. Dott. A. Giuffrè Editore, Milano, 1958.

Mohino manrioue, A.L., Pactos en el contrato de compraventa en interés del vendedor, Edit. Dykinson, Madrid, 2006. 
Moncayo Rodríguez, S., Contratos: tradición y globalización, en Transformaciones jurídicas en el contexto de la globalización. Contratos: tradición y globalización, Vol II, Edit. Arana Editores, Xalapa.

Pothier, R.J., Traité du contrat de mandat, en Oeuvres de Pothier, Tomo III, Edit. Chez I’Editeur, París, 1821.

ReINoso Barbero, F., El abogado romano «specimen Iuridicum inaugurale», en Historia de la Abogacía Española, Vol. I, Edit. Thomson Reuters Aranzadi, Pamplona, 2015.

RodríGuez GuITIÁN, A. M ${ }^{\mathrm{a}}$., El desistimiento en el contrato de servicios de profesionales liberales, en Anuario de Derecho Civil, Vol. 54, N² , Madrid, 2001.

Rossi, R., Observaciones sobre la figura del abogado en Derecho Romano, en Studi in onore di Giuseppe Grosso, Vol I, Edit. G. Diapidreli, Torino, 1970.

Serra Rodríguez, A., La relación de servicios del abogado, Edit. Tirant lo Blanc, Valencia, 1999. 
